\title{
Polymeric nanoparticles: Recent development in synthesis and application
}

\author{
S. Mallakpour ${ }^{1,2,3^{*}}$, V. Behranvand ${ }^{1}$ \\ ${ }^{1}$ Organic Polymer Chemistry Research Laboratory, Department of Chemistry, Isfahan University of Technology, \\ 84156-83111 Isfahan, Islamic Republic of Iran \\ ${ }^{2}$ Nanotechnology and Advanced Materials Institute, Isfahan University of Technology, 84156-83111 Isfahan, Islamic \\ Republic of Iran \\ ${ }^{3}$ Center of Excellence in Sensors and Green Chemistry, Department of Chemistry, Isfahan University of Technology, \\ 84156-83111 Isfahan, Islamic Republic of Iran
}

Received 18 April 2016; accepted in revised form 25 June 2016

\begin{abstract}
Nanosized particles have attractive characteristics, which have received considerable attention in the last decade. Polymeric nanoparticles (PNP)s are solid particles or particulate dispersions with size in the range of 10-1000 nm. Due to the very small size, the surface area is very large so the percentage of atoms or molecules on the surface is significantly increased, which is expected to have extensive applications in various fields such as drug delivery systems, biosensors, catalysts, nanocomposites, agriculture and environment. The aim of the present paper is to critically review enhancement in the field of synthesis and different application of novel PNPs in various area from drug delivery to composite fabrication. Literature sources were mainly taken from the publications of 2011 and later; though, for a basic depiction of the structural principles, older publications have also been cited.
\end{abstract}

Keywords: biopolymers, biocomposites, polymeric nanoparticles, drug delivery systems, biosensors

\section{Introduction to polymer nanoparticles (PNP)s}

Particles with diameters below the micron dimension: generally, in the range $10-100 \mathrm{~nm}$ are nanoparticles (NP)s [1]. Polymer-based NP (PNP) is a collective term which is given to any kind of polymer NP, but specifically is applied for nanospheres and nanocapsules [2]. The historical development of PNPs was created by Paul Ehrlich with the first experimental efforts by Ursula Scheffel. Extensive works were conducted by the group of Peter Speiser at ETH Zürich in the late 1960s and early 1970s [3].

The field of PNPs is quickly growing and playing a key role in extensive field of areas ranging from photonics, electronics, sensors, medicine, pollution control and environmental technology. PNPs have long been used as main components in established everyday coatings, paints and adhesives products. More recently, they have found applications in biomedical fields such as bio-imaging, drug delivery and diagnostics. PNP-based materials with unique physical and chemical characteristics might become future commands for the progress of new nanomaterials [4-7]. As a contribution to updating the state of knowledge and due to importance of PNPs, the present review focuses on PNPs. The aim of this review article is primarily to provide short information about traditional preparation ways of PNPs. Then, we would like to show some recently reported methods like using ultrasonic and microwave tools as other environmentally friendly approaches for the PNPs preparation in the first section. From our point of view, the use

${ }^{*}$ Corresponding author, e-mail: mallak@cc.iut.ac.ir C BME-PT 
of these methods as low cost and safe ways should be highlighted. Furthermore, their importance according to their applications discusses. We will also show some properties of them such as morphology and biological activity.

\section{Green techniques in synthesis of NPs}

The manufacturing techniques of PNPs are classified due to whether the particle formation involves a polymerization reaction or NPs are produced directly from a preformed polymer or by direct polymerization of monomers using classical polymerization or polyreactions [7, 8]. Direct polymerization of monomers can be accomplished through different polymerization techniques such as micro-emulsion, miniemulsion, surfactant-free emulsion and interfacial polymerization. The preparation of PNPs from preformed polymers can be carried out via methods like solvent evaporation, salting-out, dialysis and supercritical fluid technology. Methods like rapid expansion of supercritical solution and rapid expansion of supercritical solution into liquid solvent and surfactant-free emulsion polymerization can be successfully applied for manufacturing surfactant-free PNPs and moreover they are environment friendly [2]. In this section we want to introduce ultrasonic and microwave tools as another environmentally friendly approaches for the PNPs preparation.

\subsection{Ultrasonication}

Ultrasound (US) is presently a common laboratory tool applied to disperse NPs and colloids and to nebulize solutions into fine mixtures [9]. This method is advantageous because it is nontoxic, rapid in reaction rate, and produces very small particles [10]. US provides rather unusual reaction conditions (such as: temperatures of $\sim 5000 \mathrm{~K}$, pressures of $\sim 1 \mathrm{GPa}$, and cooling rates of $\sim 1010 \mathrm{~K} \cdot \mathrm{s}^{-1}$ ) in contrast to the traditional energy sources. In fact, acoustic cavitation causes sonochemistry. Irradiation of liquids with acoustic waves of US creates the bubbles and makes the bubbles to oscillate. The bubbles collect ultrasonic energy while growing. A bubble can overgrow and collapse within a very short lifetime and a large energy concentration is attained. Consequently, various chemical reactions can proceed at room temperature using US irradiation [11, 12]. For example, the synthesis of colloidal silver NPs by using starch as reducing and stabilizing agent under sonication was accomplished by Kumar et al. [13]. Sonochemical reduction showed a remarkable potential for producing desired particle size colloidal silver NPs. It was more environmentally friendly and safer than other synthetic methodology. A variety of 1,3,5-triaryl1,3,5-hexahydrotriazine was synthesized using ultrasound assisted reactions from the reactions of aryl amines with aqueous formaldehyde by Singh et al. [14]. The use of ultrasound provided an efficient, clean and rapid methodology for the synthesis of various 1,3,5-hexahydrotriazine derivatives. In addition, it caused greater yields than the previously reported conventional methods.

\subsection{Microwave (MW)}

A fast technique of heating materials for industrial, domestic, and medical usages is MW heating. Reduction of the reaction time, controlling the reaction conditions, monitoring of temperature, pressure, and reaction times, higher yields in shorter reaction time are key advantages of MW apparatus $[15,16]$. Medium needs to have a high dielectric constant for performing reaction in a solvent under MW irradiations. There are excellent organic solvents such as 1-methyl-2pyrrolidone (NMP), dimethylsulfoxide (DMSO) and $N, N$-dimethylformamide (DMF) for carrying out the reaction but solvents should be removed at the end of the reaction and they are also toxic $[16,17]$. Room temperature ionic liquids (IL)s efficiently absorb MW energy due to their high polarity. ILs are green organic salts consisting only of ionic species that melt being below $100^{\circ} \mathrm{C}$ or even at room temperature which have attracted much attention as solvent for the polymerization [18]. The combination of MW-assisted reactions with IL has been applied for the synthesis of various nanomaterials [19].

Recently, Sun et al. [20] synthesized fluorescent carbon dots using single precursor, ammonium citrate dibasic using cheap home-use microwave oven as a facile and ultrafast method for the first time. In 2015, Hasanpoor et al. [21] obtained ultrafine zinc oxide $(\mathrm{ZnO})$ particles with controlled morphology using microwave irradiation by various methods. They examined the effect of precursor type as well as the time and the microwave irradiation power on the structure and size of ZnO NPs. By increasing the time of synthesis needle-shaped particles with a diameter of 50- 
$150 \mathrm{~nm}$ could be attained and with increasing the microwave power flower-shaped particles were obtained.

\section{Recent development in synthesis of PNPs}

In this section, novel and modified processes for the production of PNPs through the polymerization of monomers are discussed. Till 2013, emulsion polymerization is the best-proven and most generally used method [22]. In nano-emulsion formation, the spontaneous emulsification occurs with mixing of an aqueous phase and organic phase. The aqueous phase consists of hydrophilic surfactant and water, whereas the organic phase is a homogeneous solution of lipophilic surfactant, oil and water-miscible solvent. At the end of the reaction, PNPs with very small droplets (50$100 \mathrm{~nm}$ ) will form [23]. It is known that this method requires large amounts of surfactant/co-surfactant to make small NPs which increases cost and causes difficulty of purification [8]. So, 'acoustic emulsification' as one of the powerful tools for fast and environmentally friendly emulsion production was applied by Nakabayashi et al. [22] to obtain size-controlled poly(methyl methacrylate) (PMMA) NPs. They developed a novel synthesis method for size-controlled PNPs under surfactant free conditions using sequential ultrasonic irradiation. Figure 1 shows sequential ultrasonic irradiation $(20 \mathrm{kHz} \rightarrow 500 \mathrm{kHz} \rightarrow$ $1.6 \mathrm{MHz} \rightarrow 2.4 \mathrm{MHz}$ ) steps for acoustic emulsification of a water insoluble monomer methylmethacrylate (MMA) in an aqueous medium. Polymerization happened by the addition of initiator [ammonium peroxodisulfate (APS)] and to stop the polymerization, the reaction vessel was cooled to $25^{\circ} \mathrm{C}$. PMMA

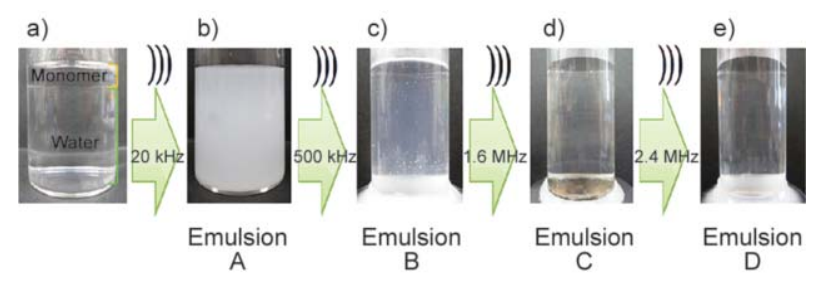

Figure 1. Photographic observations of tandem acoustic emulsification of MMA in aqueous solution. Photograph (a) represents the original MMA in aqueous solution mixture. Emulsification conditions were (b) $20 \mathrm{kHz}, 8 \mathrm{~min}$; (c) $20 \mathrm{kHz}, 8 \mathrm{~min} \rightarrow$ $500 \mathrm{kHz}, 10 \mathrm{~min}$; (d) $20 \mathrm{kHz}, 8 \mathrm{~min} \rightarrow 500 \mathrm{kHz}$, $10 \mathrm{~min} \rightarrow 1.6 \mathrm{MHz}, 10 \mathrm{~min}$; and (e) $20 \mathrm{kHz}$, $8 \mathrm{~min} \rightarrow 500 \mathrm{kHz}, 10 \mathrm{~min} \rightarrow 1.6 \mathrm{MHz}, 10 \mathrm{~min} \rightarrow$ $2.4 \mathrm{MHz}, 10 \mathrm{~min}$ [22]. samples which were synthesized from emulsion (a) showed average particle size of $241 \mathrm{~nm}$. Ultrasonication with $2.4 \mathrm{MHz}$ after $20 \mathrm{kHz}, 500 \mathrm{kHz}$, and 1.6 MHz produced particles with size of $23 \mathrm{~nm}$. Higher frequency of ultrasonication could break up the larger droplets to create smaller droplets.

Recently, Mallakpour and coworkers [24] reported in detail the use of MW irradiation for the polycondensation of diacids containing different amino acids such as phenylalanine, leucine, isoleucine, valine and alanine with aromatic diamine. Step-growth polymerization reactions were carried out in molten tetran-butylammonium bromide salt (TBAB) and IL/triphenyl phosphite (TPP) under MW irradiation. Under this conditions, poly(amide-imide) (PAI) nanostructures were obtained. According to field emission scanning electron microscopy (FE-SEM) micrographs, the PAI was obtained with the particle size of smaller than $45 \mathrm{~nm}$ in more cases. Then, the effect of ultrasonic irradiation on the size and shape of PAI NPs was investigated. FE-SEM micrographs showed that after sonication process, the size of PAI particles was decreased and reached to 28-38 nm (Figure 2).

The influence of sonication and MW irradiations on the morphology and shape of different poly(esterimide)s (PEI)s and PAIs containing natural amino acids was investigated and novel PNPs obtained by our group. Due to the presence of amino acids in their backbones, these polymers are expected to be biodegradable and hence could be categorized under environmental benign materials [25-32]. In 2013, the synthesis of several chiral nanostructure PAIs was performed under conventional heating and MW irradiation in IL media by Mallakpour and Dinari [33] to highlight the effect of MW heating. To provide the optimum reaction conditions, the influence of MW power levels and duration of heating was inspected and the results were summarized in Table 1 . The best inherent viscosity and yield were obtained after $3 \mathrm{~min}$ at $90 \%(810 \mathrm{~W})$ of $\mathrm{MW}$ power level according to this Table. The inherent viscosities of the resulting polymers under oil bath conditions (conventional heating) were in the range of $0.41-0.58 \mathrm{dL} \cdot \mathrm{g}^{-1}$ and the yields were $83-94 \%$. The FE-SEM images of the resultant PAIs prepared by MW irradiation showed nanostructure morphology of PAI with size smaller than $60 \mathrm{~nm}$ while the size of PAI synthesized under conventional heating was smaller than $70 \mathrm{~nm}$. 


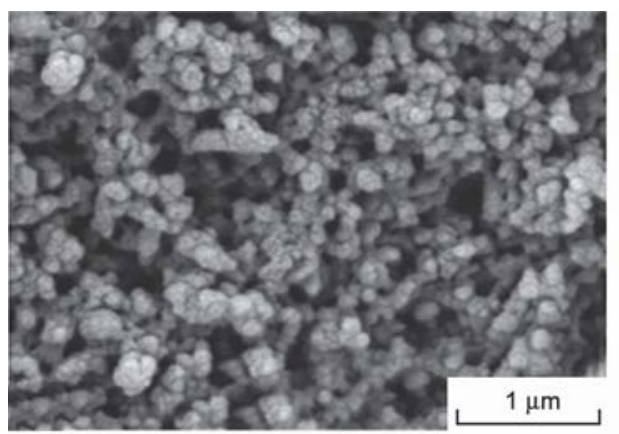

a)
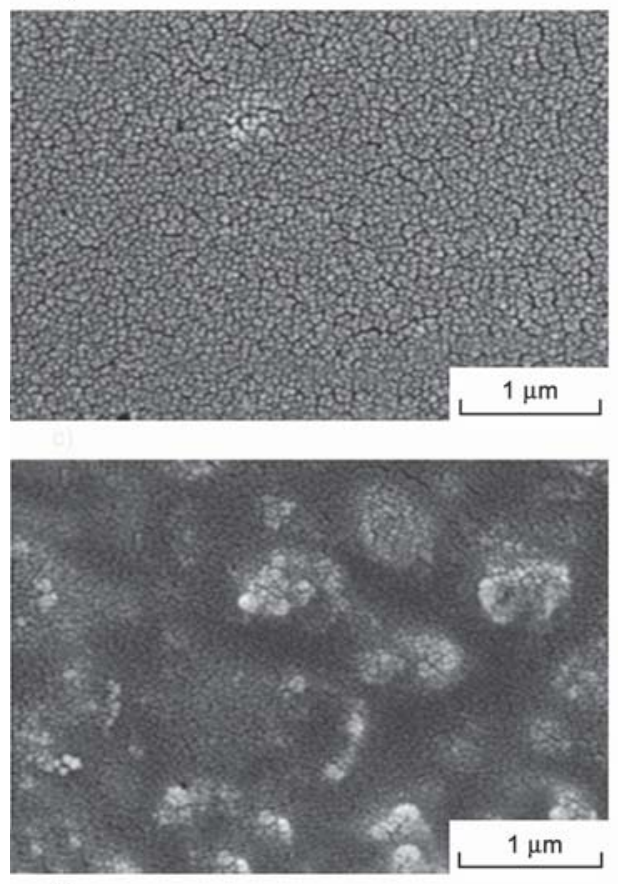

e)

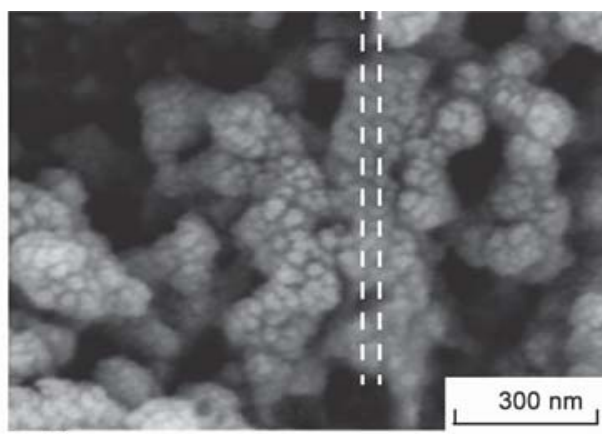

b)
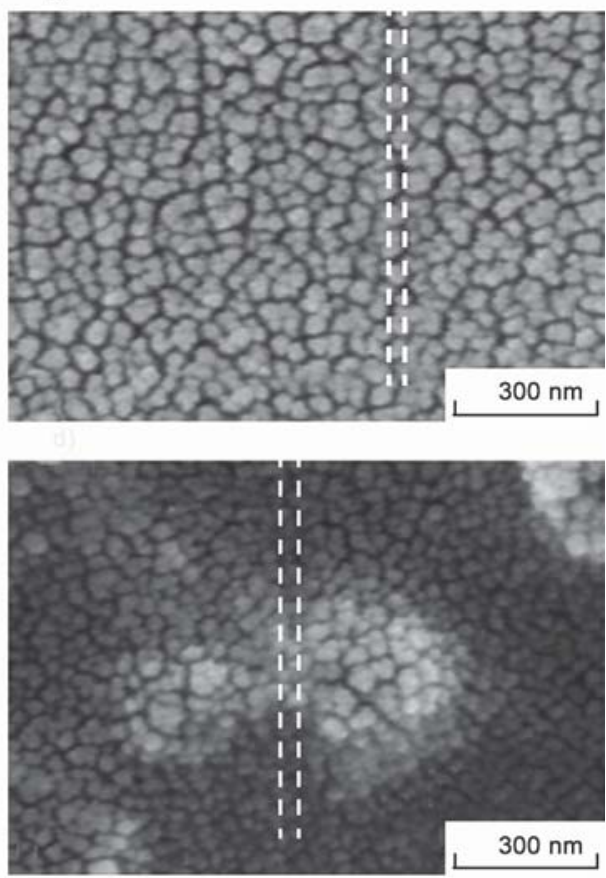

f)

Figure 2. FE-SEM micrographs of (a and b) PAI-5a, (c and d) PAI-5b, and (e and f) PAI-5c after sonication process [24]

Table 1. Optimization of reaction conditions for the preparation of PAIla using MW irradiation in molten TBAB [33].

\begin{tabular}{|l|c|c|c|c|c|}
\hline Polymer & $\begin{array}{c}\text { Microwave } \\
\text { power }\end{array}$ & $\begin{array}{c}\text { Reaction time } \\
{[\mathbf{s}]}\end{array}$ & $\begin{array}{c}\text { Yield } \\
{[\mathbf{\%}]}\end{array}$ & $\begin{array}{c}\boldsymbol{\eta}_{\text {inh }} \\
{[\mathbf{d L} / \mathbf{g}]}\end{array}$ & {$\left[\boldsymbol{\alpha}_{\mathbf{D}}{ }^{25} \mathbf{a}\right.$} \\
\hline PAI1a & 100 & 60 & 67 & 0.32 & -46.64 \\
\hline PAI1a & 100 & 120 & 62 & 0.32 & -47.02 \\
\hline PAI1a & 100 & 180 & 58 & 0.31 & -47.00 \\
\hline PAI1a & 100 & $240^{\mathrm{b}}$ & - & - & - \\
\hline PAI1a & 90 & 60 & 74 & 0.32 & -50.80 \\
\hline PAI1a & 90 & 120 & 78 & 0.38 & -52.41 \\
\hline PAI1a & 90 & 180 & 92 & 0.47 & -52.43 \\
\hline PAI1a & 90 & $240^{\mathrm{b}}$ & - & - & - \\
\hline PAI1a & 80 & 60 & 50 & 0.30 & -49.47 \\
\hline PAI1a & 80 & 120 & 57 & 0.31 & -50.52 \\
\hline PAI1a & 80 & 180 & 59 & 0.34 & -50.14 \\
\hline PAI1a & 80 & 210 & 63 & 0.35 & -49.87 \\
\hline
\end{tabular}

${ }^{\mathrm{a}}$ Measured at a concentration of $0.5 \mathrm{~g} / \mathrm{dL}$ in DMF at $25^{\circ} \mathrm{C}$,

${ }^{\mathrm{b}}$ Decomposition occurred at higher power or extended irradiation time
Mallakpour and coworkers [34, 35] prepared the optically active and biodegradable polymers containing S-valine and L-leucine amino acids under MW irradiations. The obtained PAIs showed relatively spherical morphology with particle size smaller than $50 \mathrm{~nm}$ in more cases. The results showed that the diacids and aforesaid polymers were all nontoxic to fungal growth and all samples were colonized by fungal mycelia. The resulting samples showed weight loss due to fungal degradation while no weight loss could be detected in bisphenol-A (BPA) as control. Figure 3 a demonstrates that BPA completely inhibited wheat seedling growth compared to grown seedling in control soil and lastly killed the plantlet because of its toxicity for plant growth. On the other hand, wheat seedling growth in soil containing the monomers and PAIs proposed that polymeric products have not substantial inhibition influence on normal plant growth (Figures 3b-e). 


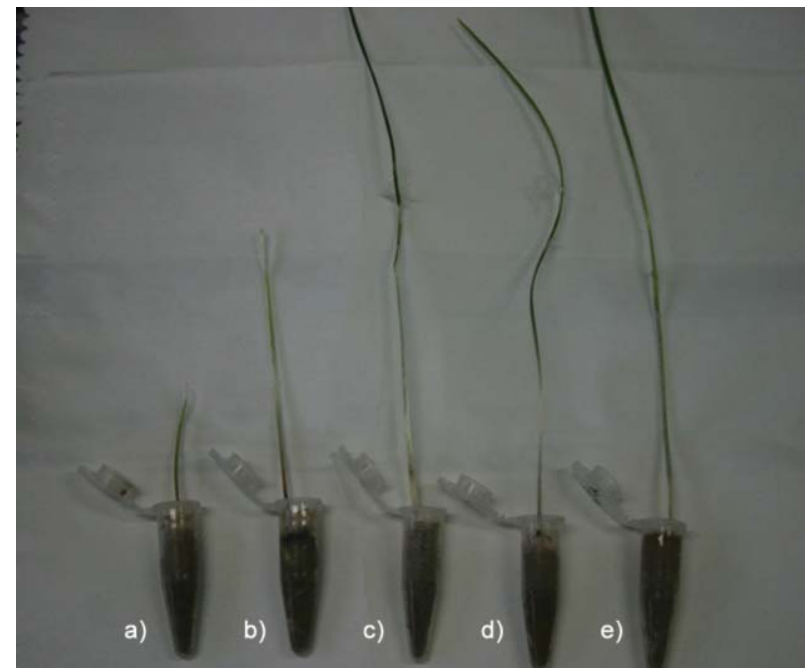

Figure 3. Effect of (b) PAI2, (c) diacid 7b, (d) diacid 7a and (e) PAI1 compared with (a) BPA on survival and growth of wheat seedlings [35]

The facile preparation of diverse and functional NPs with negatively and positively charged functionalities derived from a $\mathrm{CO}_{2}$-based triblock amphiphilic polycarbonate system from a sequential copolymerization and chemical transformation strategy was reported by Wang et al. in 2015 (Figure 4) [36].

The results indicated that polymer 5 have not formed shell-core structure. In contrast, the dynamic light scattering (DLS) studies of anionic block polymer 4 and cationic polymer $\mathbf{6}$ presented that they underwent gathering to form NPs with high uniformity, giving a similar intensity-averaged hydrodynamic diameters of $26 \pm 15 \mathrm{~nm}$. Both displayed a similar critical micelle concentration (CMC) of $66 \mathrm{mg} \cdot \mathrm{mL}^{-1}$ in DI water. They expressed that these $\mathrm{CO}_{2}$-based polycarbonates could afford a powerful platform for biomedical applications.

In 2015, Crucho and Barros [37] reported preparation of PNPs from the chemical modification of poly (D,L-lactide-co-glycolide) (PLGA) with sucrose and a cholic acid moieties (abbreviated as Suc-PLGA$\mathrm{Chol}$ ). They expressed that altering the polymer backbone not only can improve the physicochemical features of the PNPs but also their safety in biomedical applications. The synthesis of Suc-PLGA-Chol polymer conjugates was done through esterification. Virtually perfect spheres of lyophilized Suc-PLGA-Chol PNPs with a mean particle size of $260 \pm 50 \mathrm{~nm}$ were observed in SEM image. Several experimental parameters such as polymer concentration, organic solvent and evaporation rate were examined too. To evaluate dependence of the size of PNPs on the solubility parameters, acetone, acetonitrile, tetrahydrofuran as organic solvents were used for the preparation of SucPLGA-Chol PNPs. Using the most water miscible solvent (acetone) smaller particles were obtained. It could be ascribed to a more effectual solvent diffusion and faster polymer dispersion into water. The mean particle size of PNPs increased with increasing polymer concentration which is attributed to the slower solvent diffusion and formation of larger droplets during phase mixing. In 2015, Kumar's group reported an effective and simple technique for synthesizing highly fluorescent, protein-based NPs [38]. Figure 5 shows current approach of the synthesis of Prodots which made from bovine serum albumin (nBSA), glucose oxidase (nGO), horseradish perox-

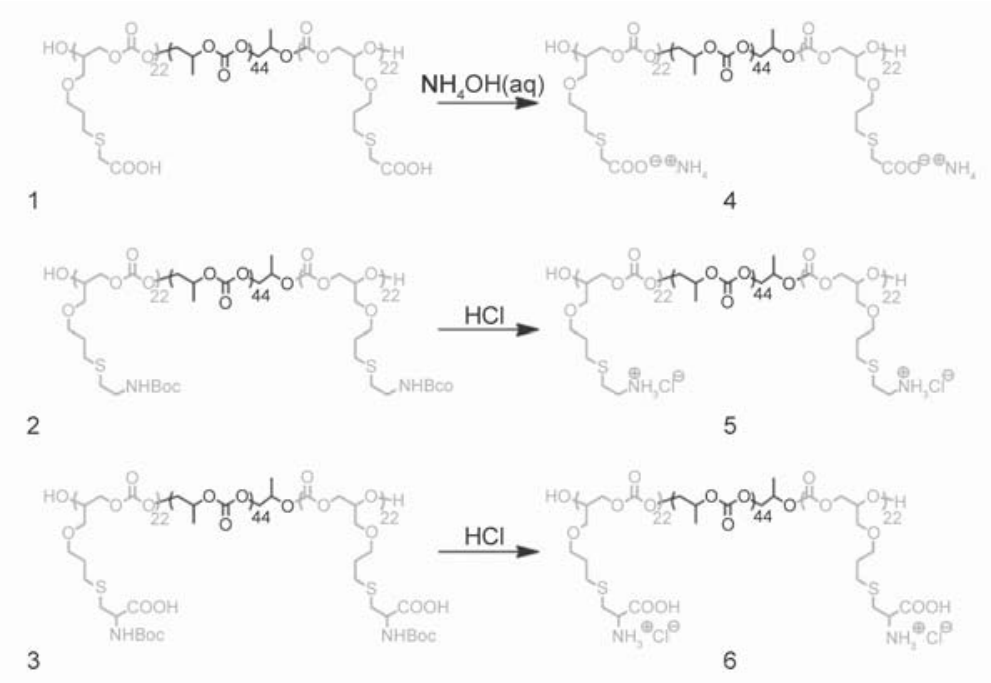

Figure 4. Synthesis of amphiphilic block polycarbonates with different charges. Boc = tert-butoxycarbonyl [36] 


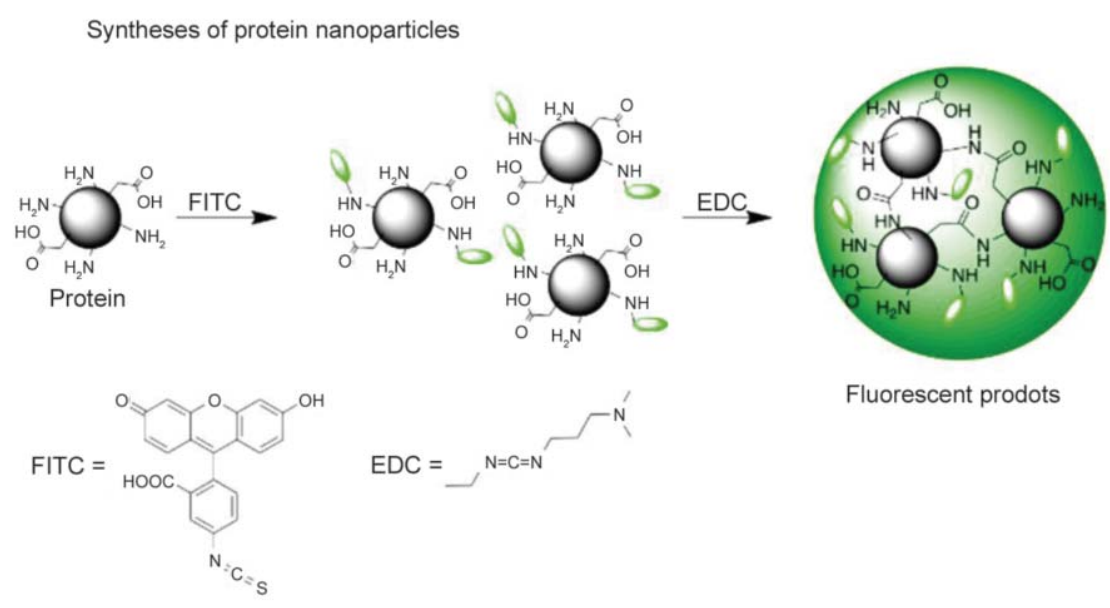

Figure 5. Prodot synthesis by FITC labeling followed by EDC cross-linking of the resulting protein clusters [38]

idase (nHRP), catalase (nCatalase), and lipase (nLipase). The amino groups of the lysine residues of proteins were coupled with fluorescein isothiocyanate (FITC) followed by controlled aggregation of proteins. Then, cross-linking the protein units was done by 1-ethyl-3-(-3-dimethylaminopropyl) carbodiimide (EDC). In this study, FITC labeling of proteins was accomplished to cross-link these clusters and form stable particles.

Transmission electron microscopy (TEM) micrographs showed $\mathrm{nGO}$ particles with size $\sim 10 \mathrm{~nm}$, while $\mathrm{nHRP}$ had a diameter of $\sim 20 \mathrm{~nm}$ and nLipase a diameter of $\sim 15 \mathrm{~nm}$. Prodots showed enhanced thermal stabilities and improved half-life besides to conserved biological activity, and these unique properties may facilitate their usage in imaging. Their aim of producing stable, fluorescent, functional, biocompatible Prodots of controllable size was testing the potential of the Prodots for cellular imaging. The results showed enhanced thermal stabilities and improved half-life besides to conserved biological activity of Prodots, and these unique properties may facilitate their usage in imaging.

Klymchenko's group [39] investigated the effect of one to two charged groups per polymer chain to obtain ultrasmall PNPs as nanocarriers. Positively charged trimethylammonium groups or negatively charged carboxylate and sulfonate were introduced into the PLGA, PMMA, and polycaprolactone (PCL). They concluded that the existence of charged groups per polymer chain can strongly decrease the size of PNPs made by nanoprecipitation(PPN). As it could be observed from TEM images, the size of particles made from uncharged chains was largest for all three polymers (above $100 \mathrm{~nm}$ ). The TEM images of uncharged and carboxy PMMA particles represented a strong affinity of aggregation. Trimethylammonium and sulfonate-bearing polymers obtained the smallest particles (below $25 \mathrm{~nm}$ ). They further exhibited that small NPs of $15 \mathrm{~nm}$ size preserve the capacity to encapsulate capably large quantities of ionic dyes with bulky counterions which creates PNPs 10-fold brighter than quantum dots of the same size.

Kausar and coworkers [40] synthesized polystyrene (PS) NPs through modified nanoprecipitation cosolvent evaporation technique (NcoSE) and two widely used strategies, i.e., solvent evaporation and NPP to examine the scope of the novel technique. The usage of modified NcoSE method improved several material properties such as the simplicity of fabrication, effectiveness, homogeneous and uniform morphology, narrow size distribution, and suitability for the composite fabrication compared to other extensively used techniques. FE-SEM image showed the spherical morphology, uniform size distribution and ordered nanostructures for obtained PSNPs/SiNPs by NcoSE method while the rough and unclear surface topology of grafted NPs were observed for PSNPs/ SiNPs synthesized through NPP and solvent evaporation methods. Silica NPs and graphite were incorporated into the obtained PS NPs to study the scope of this novel method. The results revealed the improved conductivity and thermal properties of PS and Si NP-grafted graphite CNs.

In 2015, polyamic acid (PAA) formation was attained using precipitation with a compressed fluid antisolvent technique [41]. The particle size of obtained PAA was decreased with decreased PAA con- 
centration, decreased temperature and increased pressure. Subsequently, the polyimide NPs synthesized by thermal imidization treatment of PAA.

\section{Application of PNPs}

Due to the attendance of characteristic properties presented by PNPs, these materials exhibit important roles in several applications including NCs preparation, optoelectronic and drug delivery. In this section, the design, morphology examination as well as application of two classes of PNPs are reviewed in detail: conducting polymers including polypyrrole, polyaniline (PANi), polyacetylene, poly(p-phenylene-vinylene) and polythiophene which have been a popular subject of exploration [42] and biosafe PNPs that are another important class of polymers and have many advantages such as biocompatibility and biodegradability. They are easily removed from the body by the normal metabolic path or they can have susceptibility to fungal enzymatic degradation [43-45].

\subsection{Application of conductive nanostructure polymers}

Conducting micro-/nano-structure polymers received increasing attention due to their specific electronic properties and potential applications in rechargeable batteries, electrochromic displays [46], corrosion inhibition and camouflage [47]. Conductive polymers are polymers with highly unpaired $(\pi)$ conjugated polymeric chains. In comparison to their bulk forms nanostructured conductive polymers, provide several advantageous features, such as large surface areas, improved mechanical properties for strain housing and shortened paths for charge/mass/ion transport [48]. Among the conducting polymers, polypyrrole (PPy), is one of the most widely studied electronic materials which have potential applications in drug delivery, sensors and corrosion protection [49, 50]. Samanta et al. [51] synthesized PPy NPs without the use of dopants. They loaded these PPy NPs with fluorescein sodium salt, a negatively charged model drug, and rhodamine $6 \mathrm{G}$, a positively charged model drug. PPy was used because it is an electrically conducting polymer which is both nontoxic and biocompatible. The obtained NPs exhibited good drug loading capacity. They showed that PPy NPs can be adjusted to release drugs at both acidic and basic $\mathrm{pH}$ by vary- ing the $\mathrm{pH}$. In other work, Chen et al. [52] synthesized PPy NPs with size of $50 \mathrm{~nm}$ as a metal-free ultraviolet (UV)/

near-infrared (NIR) shielding material and mixed them with polyacrylic acid (PAA) resin for the preparation of PPy-PAA full-polymer films. Their results showed that PPy-PAA films have great potential as novel coating in the application of cost-efficient energy-saving windows without potential pollution.

Alizadeh et al. [53] synthesized two types of potentiometric sensors, based on the nano-sized molecularly imprinted polymer (MIP) for high selective determination of promethazine. Two different methods containing microemulsion polymerization and suspension polymerization in silicon oil were applied to prepare nano-MIP(1) and nano-MIP(2), respectively. SEM images of the obtained polymers showed very small and spherically shaped particles. The results of the rebinding experiments represented that the binding sites of the nano-MIP(2) obtained by suspension polymerization in silicon oil had more affinity to target molecules, comparison to those of the nano-MIP(1). The results of the rebinding experiments for both MIPs in aqueous phase are shown in Table 2. It can be observed that in the case of promethazine, the adsorption ability of the nano-MIP(2) is more than that of the nano-MIP(1). In addition, it is clear that the difference between the adsorption capability of the chlorpromethazine and promethazine on the MIP(1) is more than that of nano-MIP(2), demonstrating higher selectivity of nano-MIP(2), compared to nano-MIP(1). Also, the nano-MIP(2) based sensor, displayed higher selectivity and sensitivity, compared to the nano-MIP(1) based electrode. Vaitkuviene et al. [54] synthesized pure polypyrrole (Ppy NPs) by one-step oxidative polymerization and in order to study about biocompatibility of Ppy, their cyto-compatibility was assessed. The effect of different concentration of Ppy NPs on primary mouse

Table 2. Adsorption capabilities of promethazine and chlorpromethazine to the nano-MIP(1) and nano-MIP(2) and their relevant NIPs [53]

\begin{tabular}{|l|c|c|}
\hline \multirow{2}{*}{ Polymer type } & \multicolumn{2}{|c|}{$\begin{array}{c}\text { Adsorption amount } \\
\text { [mmol/g] }\end{array}$} \\
\cline { 2 - 3 } & Promethazine & Chlorpromethazine \\
\hline nano-MIP(1) & 0.51 & 0.36 \\
\hline nano-MIP(1) & 0.47 & 0.23 \\
\hline nano-MIP(2) & 0.85 & 0.47 \\
\hline nano-MIP(2) & 0.37 & 0.26 \\
\hline
\end{tabular}


embryonic fibroblasts (MEF), mouse hepatoma cell line (MH-22A), and human T lymphocyte Jurkat cell line was examined. Achieved results exhibited that Ppy NPs at low concentrations are biocompatible, whereas at high concentrations they got cytotoxic for MEF, Jurkat and MH-22A cells, and it was concluded that cytotoxic effect is dose-dependent.

Polyaniline (PANi) is one of the oldest known and the most widely studied conducting polymer due to unique doping mechanism, its relative ease in preparation, low specific mass, good environmental stability and controllable conductivity [55-57]. It has numerous applications in rechargeable batteries, anticorrosion coatings, energy storage, photovoltaic devices, catalyst, electrochromic displays and electronic switches [58, 59]. Berti et al. [60] developed and characterized conductive PANi nanostructures for applications in electrochemical biosensing. PANi nanotubes were arranged in an ordered structure directly on an electrode surface using nanoporous alumina membranes as nano-mould. Then, grafting of PANi was done with a MIP receptor to create a model sensor for catechol detection. Actually, PANi nanostructures as conductive nanowire system allowed direct electrical connection between the synthetic receptor (MIP) and the electrode. A significantly lower detection limit for catechol attained, thus representing that the nanostructures are capable of improving the analytical performance of the sensor. A simple chemical route for synthesizing highly crystalline PANi NPs was proposed by Mahato et al. [61]. It was carried out by an in-situ polymerization of aniline monomers in a hot and dilute aqueous acidic solution. The particles with diameter ranging

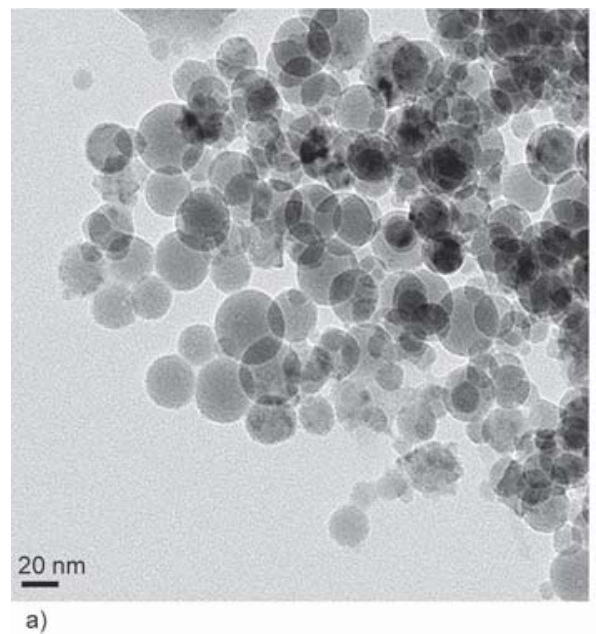

from 15 to $30 \mathrm{~nm}$ appeared as circular disk like structures in TEM image (Figure 6). The polymer exhibited good thermal stability. The PANi NPs were utilized for preparing composite with graphene NPs (2wt\% loading). It was tested as a coating material for protection of mild steel from corrosion in $0.1 \mathrm{~N}$ $\mathrm{HCl}$. Still surface with composite coating (thickness of $\sim 0.5 \mathrm{~mm}$ ) showed good corrosion protection to mild steel surface in acidic environment.

Recently, Hong et al. [62] demonstrated an acidic environmental sensing technique based on PANi NPs. In this regards, PNs were immobilized to an aminated glass substrate to sense environmental $\mathrm{pH}$ conditions. The fabricated PANi NPs showed outstanding capabilities to sense acidic environments at the single NP level. In 2016, Luo et al. [63] reported the design and production of a novel MIP conductive PANi NPs using polymeric micelle as nanoreactor for enhanced paracetamol (PCM) detection. The obtained PANi sensor showed high selectivity toward PCM. It also revealed a wider linear range over PCM concentration which was attributed to numerous effective recognition sites among the PANi matrix and it was due to the large specific surface area of PANi NPs. Considerably lower detection limit was obtained compared to previously reported PCM electrochemical sensors that should be attributed to the electrical conductivity of PANi.

\subsection{Application of biodegradable nanostructure polymers}

Biodegradable polymers can be classified as artificial or natural. Polysaccharides, nucleic acids and proteins are the illustrative natural biodegradable

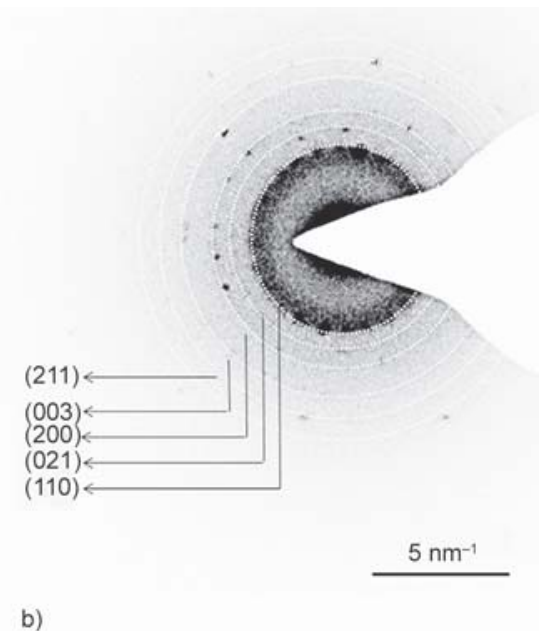

Figure 6. (a) TEM image and (b) selected area diffraction pattern of the PANi NPs [51] 
polymers. Polyesters and polyamides are typical examples for the artificial polymers [64]. Due to their biodegradability, good biocompatibility and minimal side effects, usage of biodegradable polymers for biomedical applications has increased in recent decades. The biodegradable polymeric NPs provide controlled release of bioactive compounds, and improve properties such as stability and bioavailability [65]. Nano-particulate delivery system can effectively control particle size, surface character; it enhances permeation, solubility, flexibility, and release therapeutically active agents to reach the target and attain specific activity at a predetermined rate and time $[66$, 67]. PLGA is one of the most successfully applied biodegradable nanosystem for the development of nanomedicines because it is a copolymer and can hydrolyze in the body to produce the biodegradable metabolite monomers, lactide and glycolide that are finally removed from the body by the citric acid cycle [68]. Poly(lactic acid) (PLA) is one of the most popular members of biodegradable polymers that can be naturally degraded in compost or soil by enzymes or fungi [69]. Surface grafting copolymerization of glycidyl methacrylate (GMA) on PLA NPs was accomplished through emulsion/evaporation procedure as a novel method by Li et al. [70]. Rhodamine $\mathrm{B}(\mathrm{RhB})$ initially interacts with sodium dodecyl sulfate (SDS) through electrostatic interaction to generate hydrophobic complex of SDS-RhB. According to the high-affinity of SDS-RhB with GMA, hydrophilic RhB can be successfully joined into PLA NPs. The obtained results indicated that the PLA with particle size smaller than $200 \mathrm{~nm}$ can prevent the macrophage uptake. On the other hand, the bigger PLA particles with polyethylene glycol (PEG) surface modification showed the lowest internalization by macrophage comparison to those with poly(ethylene oxide-propylene oxide) copolymer or poly (vinyl alcohol) (PVA) surface. Yoo's group reported synthesis of PLGA NPs with well-defined sizes of $\sim 70 \mathrm{~nm} \quad$ (NP70), $\sim 100 \mathrm{~nm} \quad$ (NP100), $\sim 200 \mathrm{~nm}$ (NP200), $400 \mathrm{~nm}$ (NP400), $\sim 600 \mathrm{~nm}$ (NP600) and $\sim 1000 \mathrm{~nm}$ (NP1000) [71]. The NPs showed high yield with a narrow size distribution. Uniform size distribution and mean size of $103.7 \mathrm{~nm}$ for NP100, $204.6 \mathrm{~nm}$ for NP200, $421.1 \mathrm{~nm}$ for NP400, $604.8 \mathrm{~nm}$ for NP600 and $990.0 \mathrm{~nm}$ for NP1000 were obtained. The obtained results showed as particle size becomes

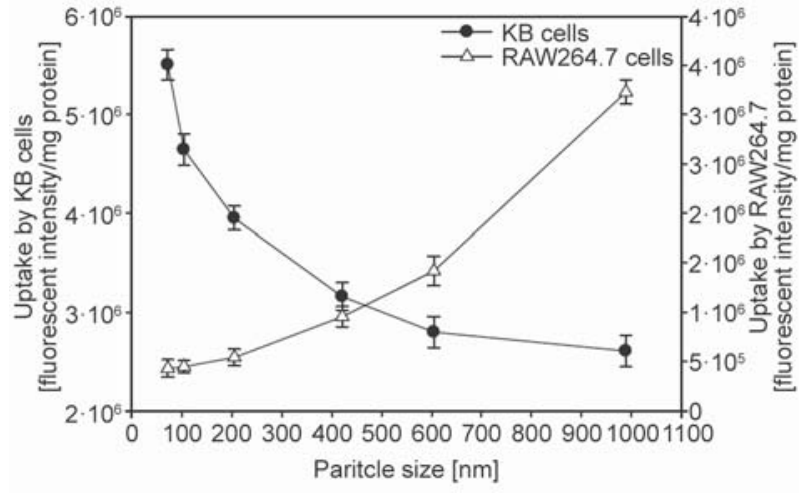

Figure 7. Quantification of the cellular uptake by KB carcinoma cells (closed circle) and RAW264.7 cells (open triangle). Data were expressed as mean $\pm \mathrm{SD}$ $(n=6)[71]$

smaller, cellular uptake and toxicities increased in tumor cells and decreased in macrophages (Figure 7). They also found that paclitaxel (PTX)-loaded NPs showed a size-dependent inhibition of tumor cell growth and the size-dependency was influenced by cellular uptake and PTX release.

Reinforcement of biomolecules within biodegradable NPs and further insertion of such carriers into tissue-engineered scaffolds will provide a controlledrelease drug delivery system. With this in mind, Nazemi et al. [72] investigated the influence of adding PLGA NPs on a chitosan-bioactive glass (CH-BG) scaffold. They prepared two groups of scaffolds (with and without NPs) and studied drug release. The SEM micrographs showed nearly spherical morphologies of the PLGA NPs which were uniformly distributed on the scaffolds pore walls. According to these images, the PLGA NPs loading into the $\mathrm{CH}-\mathrm{BG}$ scaffolds did not considerably affect the microarchitecture of the scaffolds. It was reported that the incorporation of these NPs slightly decreased the swelling behavior of the scaffolds whereas increased the mechanical strength. In addition, it was mentioned that the obtained scaffolds containing PLGA NPs could be used as bioactive bone tissue engineering scaffolds with the potential of localized delivery of biological molecules (Figure 8).

Folic acid (FA)-conjugated chitosan (CS)-functionalized PLGA nanocarriers for treatment of prostate cancer were designed by Dhas et al. [43]. PLGA NPs were coated using FA-CS conjugates for binding with folate receptors. A cell toxicity assay verified that functionalized PLGA NPs were more effective than un-functionalized ones according to modified 

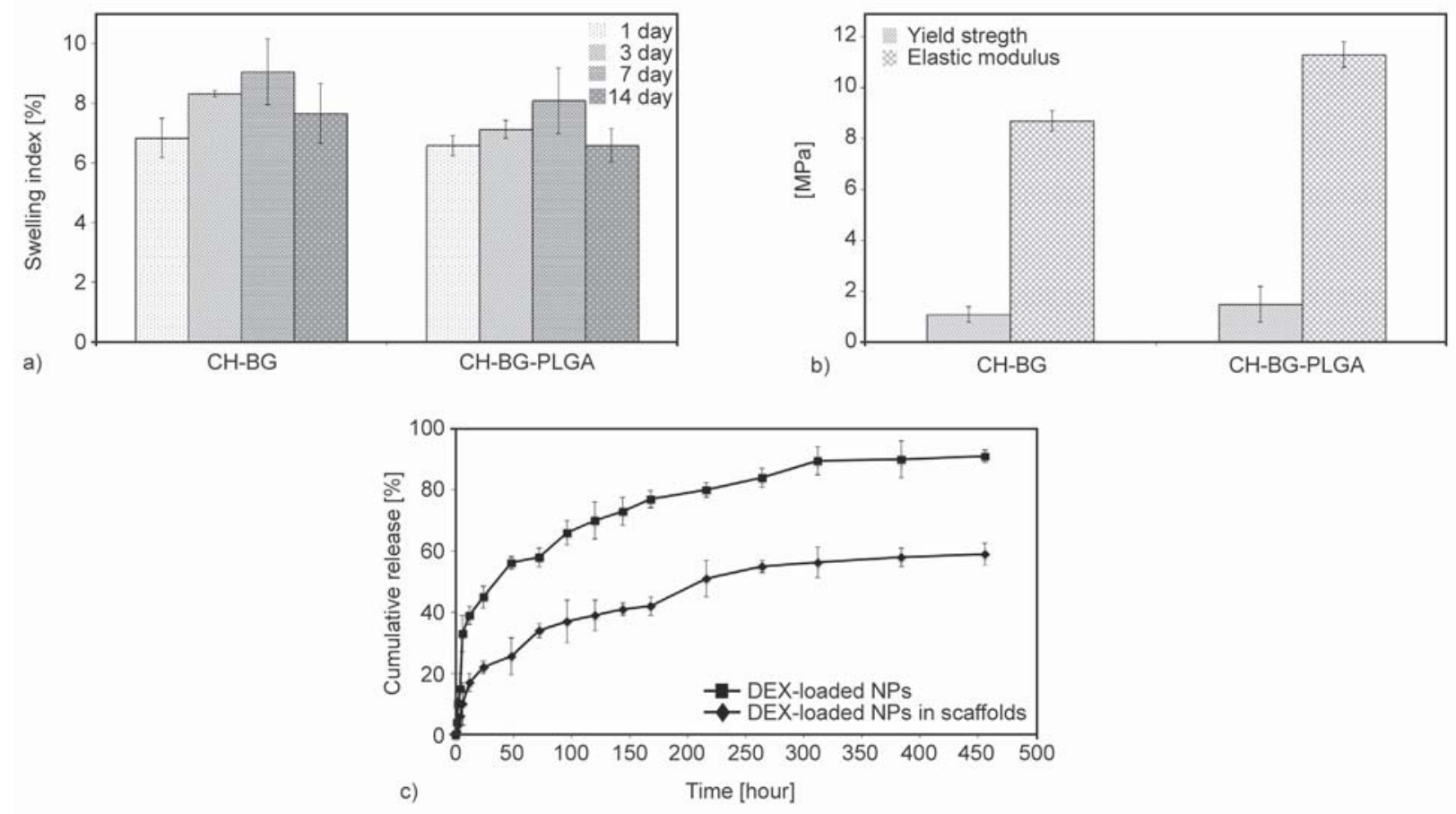

Figure 8. (a) The Swelling behavior in PBS solution, (b) the mechanical behavior of the scaffolds from compression tests, and (c) the in vitro release profile of DEX from either free NPs or NPs incorporated within the scaffolds [72]

surface, which can improve the efficiency of NPs by increasing cell targeting and/or tissue targeting and/or site-specific delivery PLGA NPs.

Mallakpour et al. [73] designed chiral bioactive PEIs containing L-phenylalanine and L-leucine amino acids with nanoscale size and good thermal stability. In vitro toxicity studies and soil biodegradation test confirmed that synthesized polymers could be decomposed by soil microorganisms hence they were biodegradable. They applied the obtained PEI containing L-leucine amino acid as matrix to prepare multiwalled carbon nanotubes (MWCNT)s bionanocomposites (BNC)s [74]. Thermal analysis showed improvement in thermal stability of the composites compared to the neat PEI by the addition of the CNTs.
Abdolmaleki and coworkers synthesized optically active and potentially biodegradable poly(esteramide)s (PEAs) based on tyrosine amino acid [75]. Nano spherical-shaped spheres of PEAs with average mean diameter as low as 79 up to $500 \mathrm{~nm}$ were obtained in this study. Higher number of colonies was counted from water extracts of soil containing diol and PEA than control treatments (Figure 9). In fact, soil burial test and dehydrogenase activity assay confirmed biodegradability of PEA NPs due to the presence of amino acid in the polymer backbone.

Afterward in 2014, they used from mentioned PEA for the fabrication of PEA/ZnO BNCs. They expressed that the synthesized NCs are expected to categorize as biologically active materials due to using

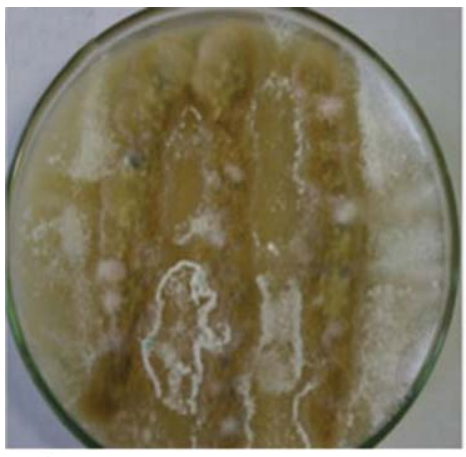

a)

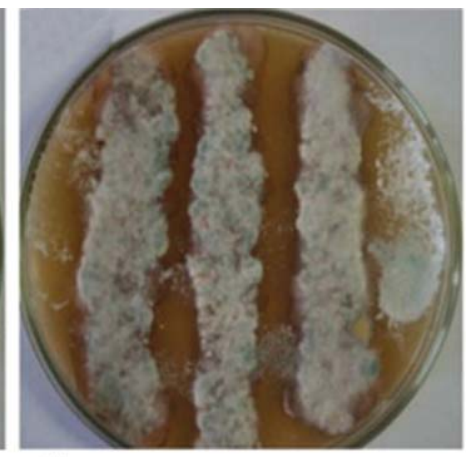

b)

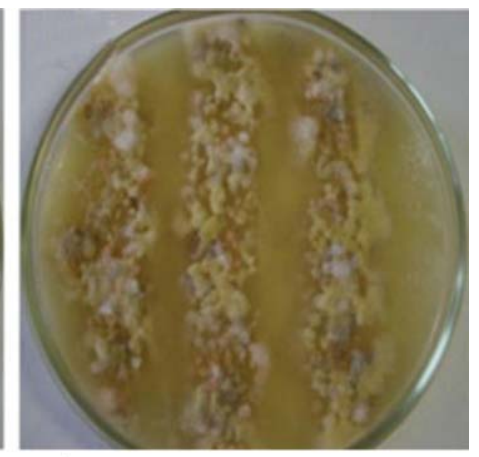

c)

Figure 9. Fungal and bacterial colonies grown from soil water extract, 6 days after inoculation on PDA Petri plates: (a) PEA, (b) diol, and (c) control [75] 
polymer based on biodegradable amino acid [76]. Hu et al. [77] studied assembled PNPs from gallic acid (GA) grafted chitosan (CS, GA-g-CS for GA grafted CS) and caseinophosphopeptides (CPP) to deliver (-)-epigallocatechin-3-gallate (EGCG) as novel functional foods. GA is a naturally occurring phenolic acid with high antioxidant activity. The GA-g-CS conjugates, compared with CS, exhibited much higher solubility under alkaline and neutral environments. Strong antioxidant activity and cytotoxicity against Caco-2 colon cancer cells were obtained by the GA-g-CS-CPP NPs. Paclitaxel is one of the most effective chemotherapeutic agents but it has poor water solubility and low therapeutic index so it needs an urgent solution to increase therapeutic efficacy of paclitaxel. According to this subject, in 2015, Thu et al. [78] designed synthesis of folate decorated paclitaxel loaded PLA-tocopheryl polyethylene glycol 1000 succinate (Fol/PTX/PLA-TPGS) NPs by a modified emulsification/solvent evaporation method. Targeting effect of the samples was evaluated by in vivo on tumor bearing mouse and in vitro on cancer cells. Research work showed that the cellular uptake of drug into cancer cells are improved by folate decorated NPs [79]. In this study, PTX loaded NPs induced better targeting influence than free PTX, and also the best operative targeting was related to Fol/ PTX/PLA NPs. For examination of in vivo targeting effect of NPs, PTX in different constructions (free PTX, PTX/PLA-TPGS NPs and Fol/PTX/PLATPGS NPs) was intravenously administrated into mouse. The Fol/PTX/PLA-TPGS NPs demonstrated the best tumor growth inhibition after 42 days of treatment (Figure 10).

Barba group synthesized new nanovectors based on copolymer of $\alpha, \beta$-poly(N-2- hydroxyethyl)-D, L-aspartamide (PHEA) and PLA to control release of lipophilic drugs [80]. The drug release happened in shorter times in comparison to PLA corresponding to the presence of hydrophilic PHEA, so the produced NPs could be introduced for semi-long term release drug delivery systems. Xu et al. [81] introduced novel PEG-PLA-polycaprolactone (PEGPLA-PCL) NPs/DNA complex as a valid gene vesicle. This complex was even better choice for transfecting rabbit bone marrow stromal cells than con-

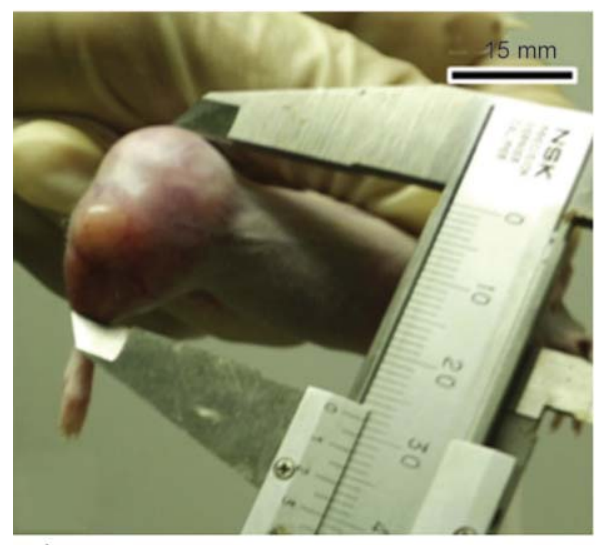

a)

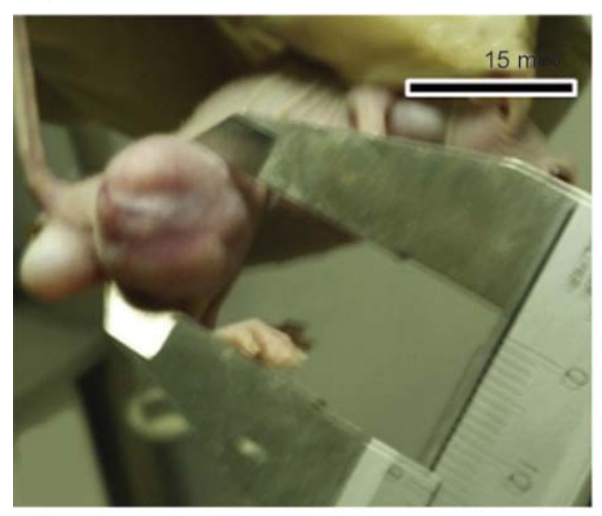

c)

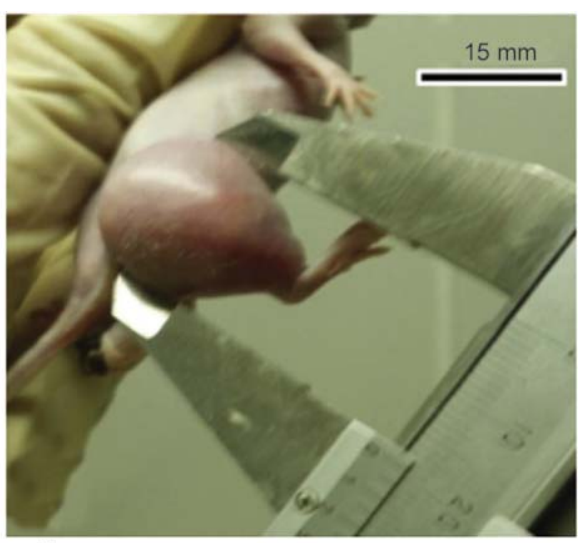

b)

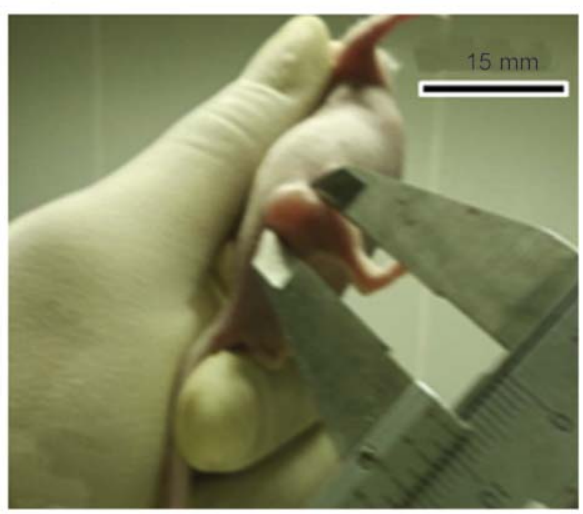

d)

Figure 10. Tumor images of mouse after 42 days of treatment: (a) control, (b) free PTX, (c) PTX/PLA-TPGS NPs and (d) Fol/PTX/PLA-TPGS NPs [79] 
ventional liposomes. The synthesized PLA/PCL particles as vehicles through supercritical fluid technology were applied by Moraes group [82]. The use of low PCL fractions (up to 20\%) obtained suitable release of $17 \alpha$-methyltestosterone hormone.

In general, encapsulation of drug happens into the polymeric particle and it is released in a controlled way by diffusion and erosion of the polymeric matrix. However, it was found that the hydrophobic character of the PLGA causes the nonspecific adsorption of plasma proteins directing to the uptake of the particles by the mononuclear phagocyte system and therefore their fast clearance from the body. It is recognized that this problem can be prevented if the particles are surface modified by the adsorption or grafting of hydrophilic polymers such as polyethylene glycol (PEG) or poly(ethylene oxide) (PEO) to improve its surface biocompatibility [83, 84]. In 2016, Gyulai et al. [83] with the aim to increase the potential of targeted drug delivery synthesized the end group derivative of Pluronics a promising drug carrier systems. Then, Pluronic and Pluronic-amine stabilized PLGA NPs were prepared by nanoprecipitation. When the Pluronic-amine derivative was applied for the NPs stabilization, intracellular antibacterial effect and in vitro efficiency increased. Also, tuneable surface modification of PLGA NPs had been accomplished by Kiss et al. in 2013 [84]. Rhodamine-6G labelled PLGA NPs were prepared by a double emulsion solvent evaporation freeze-drying method by Nkabine et al. [85]. The obtained PLGA NPs were non-cytotoxic to three different mammalian cell lines, which confirmed their safe usage as drug carrier systems.

\subsection{Application of other class of nanostructure polymers}

Amphiphilic poly(dimethylsiloxane) (PDMS)-containing poly(ether amine) (PDMS-gPEA) were synthesized by Di et al. [86]. The prepared PDMS-gPEA could directly self-assemble into stable uniformsized NPs in aqueous solution. Temperature, $\mathrm{pH}$ and ionic strength could control their aggregation. The responsive PDMS-gPEA NPs showed the unique selective encapsulation of water-soluble dye and great potential in smart separations. Kuruppuarachchi et al. [87] used from polyacrylamide NPs with potential of delivery for photodynamic agents in photody- namic therapy for cancer. Dang et al. [88] investigated preparation of PS NPs with dendrimer-Ag shell and studied their application in catalytic reduction of 4-nitrophenol (4-NP). The presence of faintly thin outer layer of PS microsphere was related to the PAMAM dendrimer shell was observed in TEM images. The attached silver NPs onto the fourth PAMAM dendrimer shell were observed too. The synthesized PS@PAMAM-Ag NPs were packed into a column for reduction of 4-NP in the presence of $\mathrm{NaBH}_{4}$ and showed adequate catalytic activity. Their results indicated that reactants could be catalyzed directly by the column system with stable flow rate and column pressure. They mentioned that this approach can decrease the loss of catalyst and prevent tedious and repeated separation using filtration or centrifugation for typical catalytic reactions. So, they concluded that it may also find application in other fields such as for antibacterial materials and in water treatment. Fritzen-Garcia, Creczynski-Pasa and coworkers [89] studied adsorption of peroxidase on PEGylated polyurethane (PU-PEG) NPs using a purified horseradish peroxidase (HRP). TEM image of the PEGylated PU NPs was shown in Figure 11a. Figure 11b displays incubated NPs by HRP with several little 'bubbles' around the NPs. As could be observed in Figure 11c, the localization of HRP molecules labeled with $\mathrm{Au}$ particles (dark spots with $10 \mathrm{~nm}$ size) is possible. Figure 11d representing the schematic of the TEM image of Figure 11c. This system was used as a modified carbon paste electrode for determination of dopamine in pharmaceutical products that showed improved detection limit and good performance in dopamine determination with less amount of enzyme adsorbed on PU-PEG NPs.

PS NPs with particle size range of 29.4-52.7 nm were manufactured via emulsion polymerization by Kong et al. [90]. Due to the lowered water to cement ratio, the use of superplasticizers has drastically altered the properties of concrete including workability, durability, impermeability and strength. Adsorption of polycarboxylate (PCE) superplasticizers on the cement surface creates the steric hindrance and electrostatic repulsion force which leads to better dispersion of cement grains in water media. Obtained results represented that the synthetic PNPs can also provide plasticizing influence to cement mixtures like as the traditional superplasticizers such 


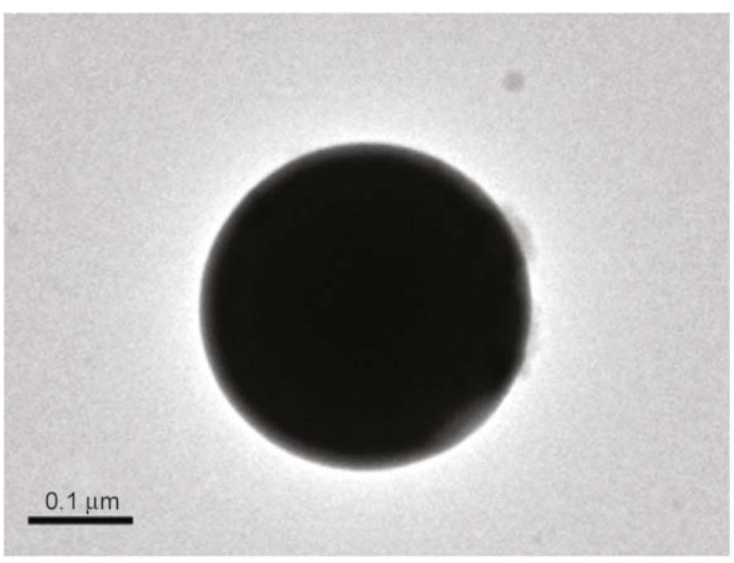

a)

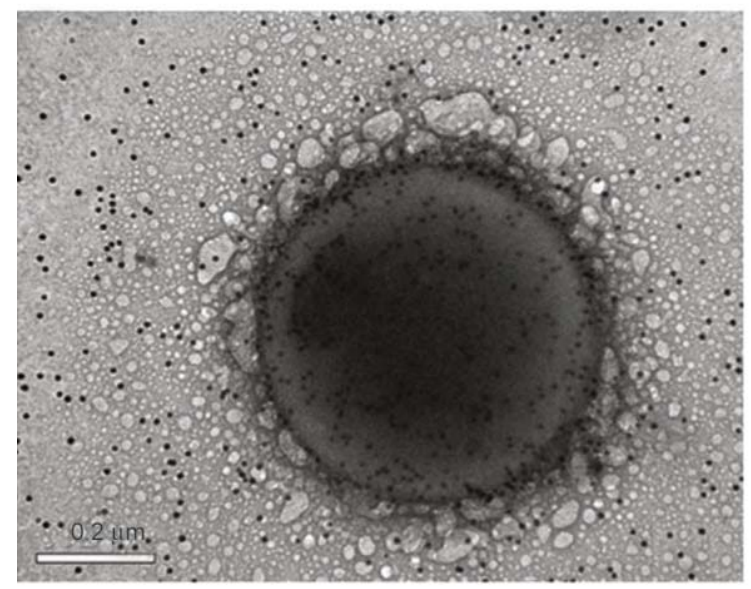

c)

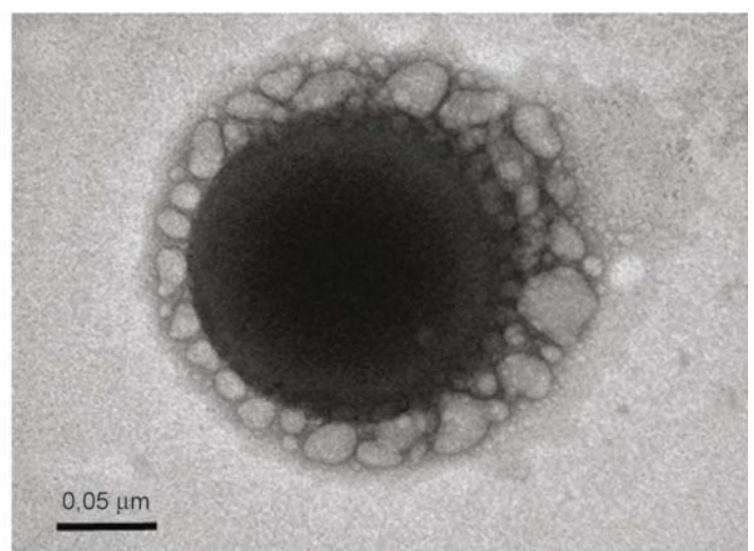

b)

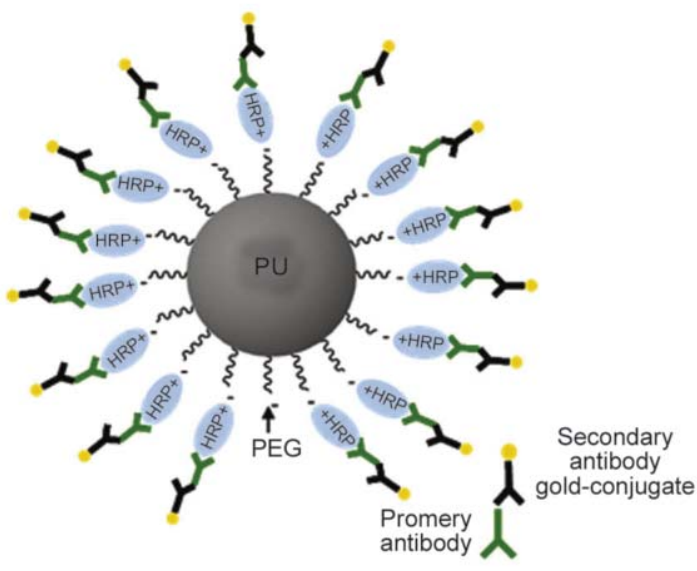

d)

Figure 11. TEM images of (a) PEGylated PU NPs; (b) in the presence of HRP and (c) HRP molecules labeled with Au particles; (d) scheme representing the image 11c [89]

as PCE. TEM image of obtained PS NPs are shown in Figure 12 and displayed narrow particle size distribution of PNPs.

According to their funding, adsorbed PS NPs on the surface of cement grains could improve the fluidity of the fresh cement pastes (fcps) effectively. The fluidity of fcps increased with increase in quantity of

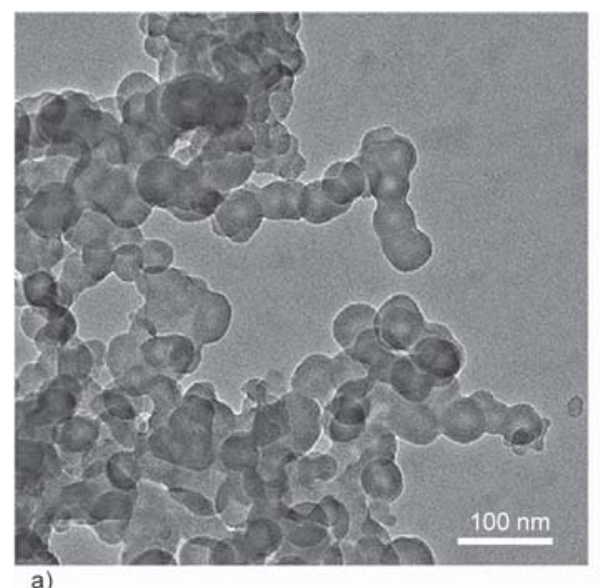

a)
PNPs. Also, the plasticizing effectiveness of PNPs was lower than that of PCE, which should be owing to their larger particle size and thicker adsorption layer on the surface of cement. Pu et al. [91] introduced semiconducting PNPs (SPNs) as near-infrared photoacoustic contrast agents for photoacoustic molecular imaging. They selected poly(cyclopentadithio-

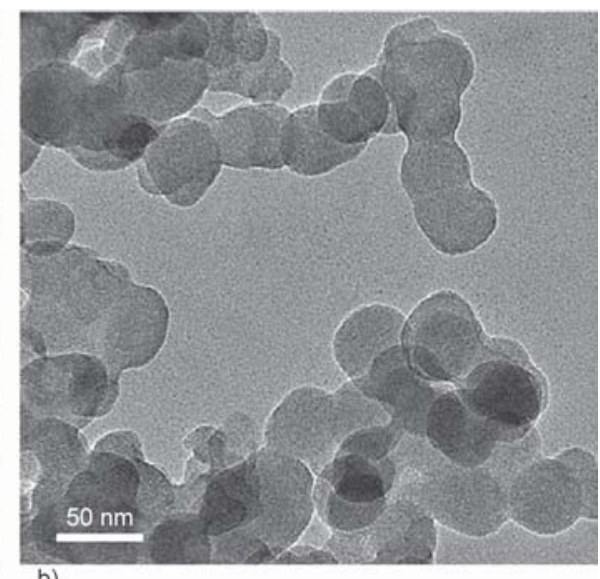

b)

Figure 12. TEM images of the synthesized PS NPs [90] 
phene-alt-benzothiadiazole) and poly(acenaphthothienopyrazine-alt-benzodithiophene) for the preparation of SPNs. Results showed that these NPs not only can generate a stronger signal than the usually used gold nanorods and single-walled carbon nanotubes on a per mass basis but also they are an ideal nanoplatform for enhancing photoacoustic molecular probes. Mallakpour et al. [92] synthesized poly (amide-benzimidazole-imide) (PABI) nanostructure containing amino acid. FE-SEM images showed nano-patterns of PABI particles with homogenous spherical shape. Then, $\mathrm{PABI} / \mathrm{Ag} \mathrm{BNC}$ was fabricated through in situ procedure. TEM image of obtained PABI/Ag NC represented good dispersion of Ag NPs in the PABI matrix. Also, resulting PABI/Ag NC exhibited antibacterial behavior rather than the pure PABI. Pure PABI was biologically active and undergoes biodegradability in soil burial test due to the presence of amino acid and also nitrogen functional groups in polymer backbone. More antibacterial effectiveness of the BNC rather than the pure PABI was obtained by embedding Ag NPs into the polymer matrix.

Because PS does not decompose in the cellular environment and is biocompatible with cells, it can be used as new drug delivery systems [93]. PS as biocompatible NPs with particle size of $44 \mathrm{~nm}$ were used as a model by Arciello and coworkers to analyze the endocytosis and uptake paths in primary human renal cortical epithelial (HRCE) cells [94]. These cells play a key role in the clearance of drugs. Results showed that PS NPs didn't exhibit any toxic influence to renal cells, and they were not released overtime. Therefore, they concluded that NPs could be used at low doses and, could to deliver drugs to specific targets upon functionalization with particular biomolecules. Also, they indicated that PS NPs entered HRCE cells through multiple mechanisms, either energy-independent or energy-dependent (endocytosis).

\section{Conclusions}

The combination of nanotechnology and polymers will be extremely useful in various applications, producing materials with unique properties. The first section of this review has provided information about recent developments in synthesis of PNPs. The using of ultrasound and MW irradiations as fast and green available methods was introduced for the preparation of PNPs too. Then, this review paper has focused on the properties and application of novel synthesized PNPs. The discussed nanostructured polymers have been applied as nanoreactors, coating materials, electrochemical biosensors, drug delivery, nanocarriers, catalysts and polymer composite fabrication. Due to main applications of PNPs in various fields, the demand for such materials is highly significant, and this is possibly one of the most important fields of research for the future. As could be observed in this review there has been a considerable research interest in the area of drug delivery using PNPs delivery systems as carriers for small and large molecules. The polymers used in delivery systems should be compatible with the body in the terms of adaptability (non-toxicity) and (non-antigenicity) and should be biodegradable and biocompatible. So, toxicity and environmental impact issues of these nanomaterials are of particular concern but are often ignored. Hence, the safety of PNPs, acute as well as long-term toxicity, should be addressed further, and special attention should be paid to off-target effects, demanding careful design and proper controls, as well as extreme caution in interpretation of data from in vivo studies. Another key issue about usage of PNPs is their potential effects on global economics, as well as speculation about various doomsday scenarios. These worries have accounted for a discussion among advocacy groups and governments on whether special statutory regulation of nanobiotechnology is warranted.

\section{Acknowledgements}

We are grateful for the financial support provided by the Research Affairs Division, Isfahan University of Technology (IUT), Isfahan. Further partial financial support from the Iran Nanotechnology Initiative Council (INIC), National Elite Foundation (NEF) and Center of Excellency in Sensors and Green Chemistry (IUT) is also gratefully acknowledged.

\section{References}

[1] Hanemann T., Szabó D. V.: Polymer-nanoparticle composites: From synthesis to modern applications. Materials, 3, 3468-3517 (2010).

DOI: $10.3390 / \mathrm{ma3} 063468$

[2] Rao J. P., Geckeler K. E.: Polymer nanoparticles: Preparation techniques and size-control parameters. Progress in Polymer Science, 36, 887-913 (2011).

DOI: 10.1016/j.progpolymsci.2011.01.001 
[3] Lu X-Y., Wu D-C., Li Z-J., Chen G-Q.: Polymer nanoparticles. Progress in Molecular Biology and Translational Science, 104, 299-323 (2011). DOI: $10.1016 /$ B978-0-12-416020-0.00007-3

[4] Wang Y-J., Larsson M., Huang W-T., Chiou S-H., Nicholls S. J., Chao J-I., Liu D-M.: The use of polymerbased nanoparticles and nanostructured materials in treatment and diagnosis of cardiovascular diseases: Recent advances and emerging designs. Progress in Polymer Science, 57, 153-178 (2016). DOI: 10.1016/j.progpolymsci.2016.01.002

[5] Nasir A., Kausar A., Younus A.: A review on preparation, properties and applications of polymeric nanoparticlebased materials. Polymer-Plastics Technology and Engineering, 54, 325-341 (2015). DOI: $10.1080 / 03602559.2014 .958780$

[6] He G., Pan Q., Rempel G. L.: Synthesis of poly(methyl methacrylate) nanosize particles by differential microemulsion polymerization. Macromolecular Rapid Communications, 24, 585-588 (2003).

DOI: $10.1002 /$ marc. 200390089

[7] Nagavarma B. V. N., Yadav H. K. S., Ayaz A., Vasudha L. S., Shivakumar H. G.: Different techniques for preparation of polymeric nanoparticles - A review. Asian Journal of Pharmaceutical and Clinical Research, 5, 16-23 (2012).

[8] Zhang G., Niu A., Peng S., Jiang M., Tu Y., Li M., Wu C.: Formation of novel polymeric nanoparticles. Accounts of Chemical Research, 34, 249-256 (2001). DOI: 10.1021/ar000011x

[9] Kharissova O. V., Kharisov B. I., Ruíz Valdés J. J., Méndez O. U.: Ultrasound in nanochemistry: Recent advances. Synthesis and Reactivity in Inorganic, Metal-Organic, and Nano-Metal Chemistry, 41, 429-448 (2011). DOI: $10.1080 / 15533174.2011 .568424$

[10] Zhang J., Du J., Han B., Liu Z., Jiang T., Zhang Z.: Sonochemical formation of single-crystalline gold nanobelts. Angewandte Chemie, 118, 1134-1137 (2006). DOI: 10.1002 /ange.200503762

[11] Safarifard V., Morsali A.: Applications of ultrasound to the synthesis of nanoscale metal-organic coordination polymers. Coordination Chemistry Reviews, 292, 1-14 (2015). DOI: $10.1016 /$ j.ccr.2015.02.014

[12] Bang J. H., Suslick K. S.: Applications of ultrasound to the synthesis of nanostructured materials. Advanced Materials, 118, 1039-1059 (2010).

DOI: 10.1002/adma.200904093

[13] Kumar B., Smita K., Cumbal L., Debut A., Pathak R. N.: Sonochemical synthesis of silver nanoparticles using starch: A comparison. Bioinorganic Chemistry and Applications, 2014, 784268/1- 784268/8 (2014). DOI: $10.1155 / 2014 / 784268$

[14] Singh A. K., Shukla S. K., Quraishi M. A.: Ultrasound mediated green synthesis of hexa-hydro triazines. Journal of Material Environment Science, 2, 403-406 (2011).
[15] Dubey R., Moorthy N. S. H. N.: Comparative studies on conventional and microwave assisted synthesis of benzimidazole and their 2-substituted derivative with the effect of salt form of reactant. Chemical and Pharmaceutical Bulletin, 55, 115-117 (2007).

DOI: $10.1248 / \mathrm{cpb} .55 .115$

[16] Mallakpour S., Rafiee Z.: Application of microwaveassisted reactions in step-growth polymerization: A review. Iranian Polymer Journal, 17, 907-935 (2008).

[17] Leadbeater N. E., Torenius H. M.: A study of the ionic liquid mediated microwave heating of organic solvents. The Journal of Organic Chemistry, 67, 3145-3148 (2002). DOI: 10.1021/jo016297g

[18] Mallakpour S., Rafiee Z.: Ionic liquids as environmentally friendly solvents in macromolecules chemistry and technology, Part I. Journal of Polymers and the Environment, 19, 447-484 (2011). DOI: $10.1007 / \mathrm{s} 10924-011-0287-3$

[19] Mallakpour S., Rafiee Z.: New developments in polymer science and technology using combination of ionic liquids and microwave irradiation. Progress in Polymer Science, 36, 1754-1765 (2011). DOI: 10.1016/j.progpolymsci.2011.03.001

[20] Sun X., He J., Meng Y., Zhang L., Zhang S., Ma X., Dey S., Zhao J., Lei Y.: Microwave-assisted ultrafast and facile synthesis of fluorescent carbon nanoparticles from a single precursor: Preparation, characterization and their application for the highly selective detection of explosive picric acid. Journal of Materials Chemistry A, 4, 4161-4171 (2016). DOI: $10.1039 / \mathrm{C} 5 \mathrm{TA} 10027 \mathrm{E}$

[21] Hasanpoor M., Aliofkhazraei M., Delavari H.: Microwave-assisted synthesis of zinc oxide nanoparticles. Procedia Materials Science, 11, 320-325 (2015). DOI: $10.1016 /$ j.mspro.2015.11.101

[22] Nakabayashi K., Kojima M., Inagi S., Hirai Y., Atobe M.: Size-controlled synthesis of polymer nanoparticles with tandem acoustic emulsification followed by soapfree emulsion polymerization. ACS Macro Letters, 2, 482-484 (2013). DOI: $10.1021 / \mathrm{mz} 4001817$

[23] Sundar S., Kundu J., Kundu S. C.: Biopolymeric nanoparticles. Science and Technology of Advanced Materials, 11, 1-13 (2010). DOI: $10.1088 / 1468-6996 / 11 / 1 / 014104$

[24] Mallakpour S., Zadehnazari A.: Simple and efficient microwave-assisted polycondensation for preparation of chiral poly(amide-imide)s having pendant phenol moiety. Polymer Science Series B, 54, 314-322 (2012). DOI: $10.1134 / \mathrm{S} 1560090412060048$

[25] Mallakpour S., Zeraatpisheh F.: Novel chiral and organosoluble nanostructure poly(ester-imide)s containing $N, N^{\prime}-\left(3,3^{\prime}, 4,4^{\prime}\right.$-benzophenonetetracarboxylic)3,3',4,4'-diimido-bis-(L-tyrosine methyl ester) as a new amino acid based diol: Production, morphology, and thermal properties. Designed Monomers and Polymers, 16, 488-497 (2013).

DOI: $10.1080 / 15685551.2012 .747167$ 
[26] Mallakpour S., Zadehnazari A.: Synergic effects of molten ionic liquid and microwave irradiation in preparation of optically active nanostructured poly(amideimide)s containing amino acid and dopamine moiety. Polymer-Plastics Technology and Engineering, 51, 1090-1096 (2012).

DOI: $10.1080 / 03602559.2012 .689059$

[27] Mallakpour S., Ahmadizadegan H.: Poly(amide-imide)s obtained from 3,5-diamino- $N$-(thiazol-2-yl)-benzamide and dicarboxylic acids containing various amino acid units: Production, characterization and morphological investigation. High Performance Polymers, 25, 156164 (2013).

DOI: $10.1177 / 0954008312459547$

[28] Mallakpour S., Zarei M.: Novel, thermally stable and chiral poly(amide-imide)s derived from a new diamine containing pyridine ring and various amino acid-based diacids: Fabrication and characterization. High Performance Polymers, 25, 245-253 (2013).

DOI: $10.1177 / 0954008312461658$

[29] Mallakpour S., Dinari M.: Novel nanostructure amino acid-based poly(amide-imide)s enclosing benzimidazole pendant group in green medium: Fabrication and characterization. Amino Acids, 43, 1605-1613 (2012). DOI: $10.1007 / \mathrm{s} 00726-012-1236-8$

[30] Mallakpour S., Zadehnazari A.: Microwave-assisted synthesis and morphological characterization of chiral poly(amide-imide) nanostructures in molten ionic liquid salt. Advances in Polymer Technology, 32, 21333/121333/12 (2013).

DOI: $10.1002 / \mathrm{adv} .21333$

[31] Mallakpour S., Zadehnazari A.: Tailored synthesis of nanostructured polymer thin films from optically active and thermally stable poly(amide-co-imide)s containing hydroxyl pendant groups in a green ionic solvent. Polymer-Plastics Technology and Engineering, 51, 1097 1105 (2012).

DOI: $10.1080 / 03602559.2012 .689060$

[32] Mallakpour S., Zadehnazari A.: New organosoluble, thermally stable, and nanostructured poly(amide-imide)s with dopamine pendant groups: Microwave-assisted synthesis and characterization. International Journal of Polymer Analysis and Characterization, 17, 408-416 (2012).

DOI: 10.1080/1023666X.2012.669646

[33] Mallakpour S., Dinari M.: Straightforward and green method for the synthesis of nanostructure poly(amideimide)s-containing benzimidazole and amino acid moieties by microwave irradiation. Polymer Bulletin, 70, 1049-1064 (2013).

DOI: $10.1007 / \mathrm{s} 00289-012-0875-\mathrm{y}$

[34] Mallakpour S., Khani M.: Microwave-assisted construction of nanostructured poly(amide-imide)s containing environmentally friendly natural amino acids via implementation of molten salt ionic liquid as an activating media. Polymer-Plastics Technology and Engineering, 53, 38-45 (2014).

DOI: $\underline{10.1080 / 03602559.2013 .843687}$
[35] Mallakpour S., Khani M., Sabzalian M. R.: Synthesis and biodegradability assessment of poly(amide-imide)s containing $\mathrm{N}$-trimellitylimido-L-amino acid and 5-(2benzimidazole)-1,3-phenylenediamine. Polymer Bulletin, 71, 2159-2172 (2014).

DOI: $10.1007 / \mathrm{s} 00289-014-1179-1$

[36] Wang Y., Fan J., Darensbourg D. J.: Construction of versatile and functional nanostructures derived from $\mathrm{CO}_{2}$-based polycarbonates. Angewandte Chemie International Edition, 54, 10206-10210 (2015).

DOI: $10.1002 /$ anie.201505076

[37] Crucho C. I. C., Barros M. T.: Formulation of functionalized PLGA polymeric nanoparticles for targeted drug delivery. Polymer, 68, 41-46 (2015).

DOI: $10.1016 /$ j.polymer.2015.04.083

[38] Deshapriya I. K., Stromer B. S., Pattammattel A., Kim C. S., Iglesias-Bartolome R., Gonzalez-Fajardo L., Patel V., Gutkind J. S., Lu X., Kumar C. V.: Fluorescent, bioactive protein nanoparticles (prodots) for rapid, improved cellular uptake. Bioconjugate Chemistry, 26, 396-404 (2015).

DOI: $10.1021 / \mathrm{bc} 500621 \mathrm{~h}$

[39] Reisch A., Runser A., Arntz Y., Mély Y., Klymchenko A. S.: Charge-controlled nanoprecipitation as a modular approach to ultrasmall polymer nanocarriers: Making bright and stable nanoparticles. ACS Nano, 5, 51045116 (2015). DOI: $10.1021 /$ acsnano.5b00214

[40] Nasir A., Kausar A., Younus A.: Novel hybrids of polystyrene nanoparticles and silica nanoparticles-graftedgraphite via modified technique. Polymer-Plastics Technology and Engineering, 54, 1122-1134 (2015). DOI: 10.1080/03602559.2014.996904

[41] Lin H-W., Tan C-S.: Preparation of polyamic acid and polyimide nanoparticles by compressed fluid antisolvent and thermal imidization. The Journal of Supercritical Fluids, 99, 103-111 (2015).

DOI: $10.1016 /$ j.supflu.2015.01.028

[42] Chabukswar V., Dhomase N., Bhavsar S., Horne A., Mohite K., Gaikwad V.: Studies on morphology and conductivity of poly ( $N$-methyl aniline) nanoparticles prepared in nonstirred reaction medium. Macromolecular Symposia, 298, 43-50 (2010).

DOI: $10.1002 /$ masy.201000019

[43] Dhas N. L., Ige P. P., Kudarha R. R.: Design, optimization and in-vitro study of folic acid conjugated-chitosan functionalized PLGA nanoparticle for delivery of bicalutamide in prostate cancer. Powder Technology, 283, 234-245 (2015).

DOI: 10.1016/j.powtec.2015.04.053

[44] Mallakpour S., Behranvand V.: Surface treatment of nano $\mathrm{ZnO}$ using 3,4,5,6-tetrabromo- $N$-(4-hydroxyphenyl)-phthalamic acid as novel coupling agent for the preparation of poly(amide-imide)/ZnO nanocomposites. Colloid and Polymer Science, 292, 2275-2283 (2014). DOI: $10.1007 / \mathrm{s} 00396-014-3264-2$ 
[45] Mallakpour S., Dinari M.: Progress in synthetic polymers based on natural amino acids. Journal of Macromolecular Science Part A: Pure and Applied Chemistry, 48, 644-679 (2011). DOI: $10.1080 / 15226514.2011 .586289$

[46] Ashrafi A., Golozar M. A., Mallakpour S.: Morphological investigations of polypyrrole coatings on stainless steel. Synthetic Metals, 156, 1280-1285 (2006).

DOI: $10.1016 /$ j.synthmet.2006.09.014

[47] Ayad M. M., Salahuddin N., Ali M.: Polyaniline-organoclay nanocomposites as curing agent for epoxy: Preparation and characterization. Polymer Composites, 30, 467-473 (2009).

DOI: $10.1002 /$ pc.20599

[48] Shi Y., Peng L., Ding Y., Zhao Y., Yu G.: Nanostructured conductive polymers for advanced energy storage. Chemical Society Reviews, 44, 6684-6696 (2015). DOI: $10.1039 / \mathrm{c} 5 \mathrm{cs} 00362 \mathrm{~h}$

[49] Moghaddam A. B., Nazari T., Badraghi J., Kazemzad M.: Synthesis of $\mathrm{ZnO}$ nanoparticles and electrodeposition of polypyrrole/ZnO nanocomposite film. International Journal of Electrochemistry Science, 4, 247-257 (2009).

[50] Tai H., Jiang Y., Xie G., Yu J., Zhao M.: Self-assembly of $\mathrm{TiO}_{2}$ /polypyrrole nanocomposite ultrathin films and application for an $\mathrm{NH}_{3}$ gas sensor. International Journal of Environmental Analytical Chemistry, 87, 539-551 (2007). DOI: $10.1080 / 03067310701272954$

[51] Samanta D., Meiser J. L., Zare N. R.: Polypyrrole nanoparticles for tunable, $\mathrm{pH}$-sensitive and sustained drug release. Nanoscale, 7, 9497-9504 (2015).

DOI: $10.1039 / \mathrm{c} 5 \mathrm{nr} 02196 \mathrm{k}$

[52] Chen X., Yu N., Zhang L., Liu Z., Wang Z., Chen Z.: Synthesis of polypyrrole nanoparticles for constructing full-polymer UV/NIR-shielding film. RSC Advances, 5, 96888-96895 (2015).

DOI: $10.1039 / \mathrm{c} 5 \mathrm{ra} 20164 \mathrm{k}$

[53] Alizadeh T., Ganjali M. R., Akhoundian M.: Synthesis and application of different nano-sized imprinted polymers for the preparation of promethazine membrane electrodes and comparison of their efficiencies. International Journal of Electrochemical Science, 7, 7655 7674 (2012).

[54] Vaitkuviene A., Kaseta V., Voronovic J., Ramanauskaite G., Biziuleviciene G., Ramanaviciene A., Ramanavicius A.: Evaluation of cytotoxicity of polypyrrole nanoparticles synthesized by oxidative polymerization. Journal of Hazardous Materials, 250-251, 167-174 (2013). DOI: $10.1016 /$ j.jhazmat.2013.01.038

[55] Patil S. L., Chougule M. A., Pawar S. G., Sen S., Patil V. B.: Effect of camphor sulfonic acid doping on structural, morphological, optical and electrical transport properties on polyaniline-ZnO nanocomposites. Soft Nanoscience Letters, 2, 46-53 (2012).

DOI: $10.4236 / \mathrm{snl} .2012 .23009$
[56] Phang S. W., Tadokoro M., Watanabe J., Kuramoto N.: Effect of $\mathrm{Fe}_{3} \mathrm{O}_{4}$ and $\mathrm{TiO}_{2}$ addition on the microwave absorption property of polyaniline micro/nanocomposites. Polymers for Advanced Technologies, 20, 550-557 (2009).

DOI: $10.1002 /$ pat.1381

[57] Song E., Choi J-W.: Conducting polyaniline nanowire and its applications in chemiresistive sensing. Nanomaterials, 3, 498-523 (2013).

DOI: $10.3390 /$ nano3030498

[58] Hu C., Chen Y., Chen X., Zhang B., Yang J., Zhou J., Zhang M. Q.: Enhancement of photoresponse properties of conjugated polymers/inorganic semiconductor nanocomposites by internal micro-magnetic field. Chemistry A European Journal, 18, 1467-1475 (2012).

DOI: $10.1002 /$ chem.201101769

[59] Bhadra J., Sarkar D.: Size variation of polyaniline nanoparticles dispersed in polyvinyl alcohol matrix. Bulletin of Materials Science, 33, 519-523 (2010).

DOI: 10.1007/s12034-010-0079-8

[60] Berti F., Todros S., Lakshmi D., Whitcombe M. J., Chianella I., Ferroni M., Piletsky S. A., Turner A. P. F., Marrazza G.: Quasi-monodimensional polyaniline nanostructures for enhanced molecularly imprinted polymerbased sensing. Biosensors and Bioelectronics, 26, 497503 (2010). DOI: $10.1016 /$ j.bios.2010.07.063

[61] Mahato N., Parveen N., Cho M. H.: Synthesis of highly crystalline polyaniline nanoparticles by simple chemical route. Materials Letters, 161, 372-374 (2015).

DOI: $10.1016 /$ j.matlet.2015.08.138

[62] Hong Y., Hwang S., Yoon D. S., Yang J.: Scattering analysis of single polyaniline nanoparticles for acidic environmental sensing. Sensors and Actuators B: Chemical, 218, 31-36 (2015).

DOI: $10.1016 /$ j.snb.2015.04.098

[63] Luo J., Sun J., Huang J., Liu X.: Preparation of watercompatible molecular imprinted conductive polyaniline nanoparticles using polymeric micelle as nanoreactor for enhanced paracetamol detection. Chemical Engineering Journal, 283, 1118-1126 (2016).

DOI: $10.1016 /$ j.cej.2015.08.041

[64] Zhang S., Wu Y., He B., Luo K., Gu Z.: Biodegradable polymeric nanoparticles based on amphiphilic principle: Construction and application in drug delivery. Science China Chemistry, 57, 461-475 (2014).

DOI: $10.1007 / \mathrm{s} 11426-014-5076-0$

[65] Marin E., Briceño M. I., Caballero-George C.: Critical evaluation of biodegradable polymers used in nanodrugs. International Journal of Nanomedicine, 8, 30713091 (2013).

DOI: $10.2147 /$ IJN.S47186

[66] Bennet D., Kim S.: Polymer nanoparticles for smart drug delivery. in 'Application of nanotechnology in drug delivery’ (Sezer E. A. D.) InTech, Rijeka, 257-310 (2014).

DOI: $10.5772 / 58422$ 
[67] Soppimath K. S., Aminabhavi T. M., Kulkarni A. R., Rudzinski W. E.: Biodegradable polymeric nanoparticles as drug delivery devices. Journal of Controlled Release, 70, 1-20 (2001). DOI: $10.1016 / \mathrm{S} 0168-3659(00) 00339-4$

[68] Kerimoğlu O., Alarçin E.: Poly(lactic-co-glycolic acid) based drug delivery devices for tissue engineering and regenerative medicine. ANKEM Derg, 26, 86-98 (2012). DOI: 10.5222 /ankem.2012.086

[69] Eili M., Shameli K., Ibrahim N. A., Yunus W. M. Z. W.: Degradability enhancement of poly(lactic acid) by stearate- $\mathrm{Zn}_{3} \mathrm{Al} \mathrm{LDH}$ nanolayers. International Journal of Molecular Sciences, 13, 7938-7951 (2012). DOI: $10.3390 /$ ijms13077938

[70] Li F., Zhu A., Song X., Ji L., Wang J.: The internalization of fluorescence-labeled PLA nanoparticles by macrophages. International Journal of Pharmaceutics, 453, 506-513 (2013).

DOI: $10.1016 /$ j.ijpharm.2013.06.033

[71] Choi J-S., Cao J., Naeem M., Noh J., Hasan N., Choi H-K., Yoo J-W.: Size-controlled biodegradable nanoparticles: Preparation and size-dependent cellular uptake and tumor cell growth inhibition. Colloids and Surfaces B: Biointerfaces, 122, 545-551 (2014). DOI: $10.1016 /$ j.colsurfb.2014.07.030

[72] Nazemi K., Azadpour P., Moztarzadeh F., Urbanska A. M., Mozafari M.: Tissue-engineered chitosan/bioactive glass bone scaffolds integrated with PLGA nanoparticles: A therapeutic design for on-demand drug delivery. Materials Letters, 138, 16-20 (2015).

DOI: 10.1016/j.matlet.2014.09.086

[73] Mallakpour S., Soltanian S., Sabzalian M. R.: Fabrication and in vitro degradation study of novel optically active polymers derived from amino acid containing diacids and 4,4'-thiobis(2-tert-butyl-5-methylphenol). Journal of Polymer Research, 18, 1679-1686 (2011). DOI: 10.1007/s10965-011-9573-y

[74] Mallakpour S., Soltanian S.: Functionalized multi-wall carbon nanotube reinforced poly(ester-imide) bionanocomposites containing L-leucine amino acid units. Journal of Polymer Research, 21, 335-342 (2014).

DOI: 10.1007/s10965-013-0335-x

[75] Abdolmaleki A., Mallakpour S., Borandeh S., Sabzalian M. R.: Fabrication of biodegradable poly(ester-amide)s based on tyrosine natural amino acid. Amino Acids, 42, 1997-2007 (2012).

DOI: 10.1007/s00726-011-0931-1

[76] Abdolmaleki A., Mallakpour S., Borandeh S.: Tailored functionalization of $\mathrm{ZnO}$ nanoparticle via reactive cyclodextrin and its bionanocomposite synthesis. Carbohydrate Polymers, 103, 32-37 (2014).

DOI: 10.1016/j.carbpol.2013.12.013
[77] Hu B., Wang Y., Xie M., Hu G., Ma F., Zeng X.: Polymer nanoparticles composed with gallic acid grafted chitosan and bioactive peptides combined antioxidant, anticancer activities and improved delivery property for labile polyphenols. Journal of Functional Foods, 15, 593-603 (2015).

DOI: $10.1016 / \mathrm{j} . j \mathrm{ff} .2015 .04 .009$

[78] Thu H. P., Nam N. H., Quang B. T., Son H. A., Toan N. L., Quang D. T.: In vitro and in vivo targeting effect of folate decorated paclitaxel loaded PLA-TPGS nanoparticles. Saudi Pharmaceutical Journal, 23, 683-688 (2015).

DOI: $10.1016 /$ j.jsps.2015.02.002

[79] Zhang H., Li F., Yi J., Gu C., Fan L., Qiao Y., Tao Y., Cheng C., Wu H.: Folate-decorated maleilated pullulan-doxorubicin conjugate for active tumor-targeted drug delivery. European Journal of Pharmaceutical Sciences, 42, 517-526 (2011).

DOI: $10.1016 /$ j.ejps.2011.02.006

[80] Cavallaro G., Craparo E. F., Sardo C., Lamberti G., Barba A. A., Dalmoro A.: PHEA-PLA biocompatible nanoparticles by technique of solvent evaporation from multiple emulsions. International Journal of Pharmaceutics, 495, 719-727 (2015).

DOI: $10.1016 /$ j.ijpharm.2015.09.050

[81] Xu X., Yang J., Ding L., Li J.: Bone morphogenetic protein-2-encapsulated grafted-poly-lactic acid-polycaprolactone nanoparticles promote bone repair. Cell Biochemistry and Biophysics, 71, 215-225 (2015). DOI: $10.1007 / \mathrm{s} 12013-014-0187-y$

[82] Sacchetin P. S. C., Setti R. F., de Tarso Vieira e Rosa P., Moraes Â. M.: Properties of PLA/PCL particles as vehicles for oral delivery of the androgen hormone $17 \alpha$ methyltestosterone. Materials Science and Engineering: C, 58, 870-881 (2016).

DOI: $10.1016 /$ j.msec.2015.09.071

[83] Gyulai G., Magyar A., Rohonczy J., Orosz J., Yamasaki M., Bősze Sz., Kiss É.: Preparation and characterization of cationic pluronic for surface modification and functionalization of polymeric drug delivery nanoparticles. Express Polymer Letters, 10, 216-226 (2016). DOI: $10.3144 /$ expresspolymlett.2016.20

[84] Kiss É., Gyulai G., Pénzes Cs. B., Idei M., Horváti K., Bacsa B., Bősze Sz.: Tuneable surface modification of PLGA nanoparticles carrying new antitubercular drug candidate. Colloids and Surfaces A: Physicochemical and Engineering Aspects, 458, 178-186 (2014). DOI: $10.1016 /$ j.colsurfa.2014.05.048

[85] Nkabinde L. A., Shoba-Zikhali L. N. N., SemeteMakokotlela B., Kalombo L., Swai H., Grobler A., Hamman J. H.: Poly (D,L-lactide-co-glycolide) nanoparticles: Uptake by epithelial cells and cytotoxicity. Express Polymer Letters, 8, 197-206 (2014). DOI: $10.3144 /$ expresspolymlett.2014.23 
[86] Di C., Jiang X., Wang R., Yin J.: Multi-responsive polymer nanoparticles from the amphiphilic poly(dimethylsiloxane) (PDMS)-containing poly(ether amine) (PDMSgPEA) and its potential application for smart separation. Journal of Materials Chemistry, 21, 4416-4423 (2011).

DOI: $10.1039 / \mathrm{c} 0 \mathrm{jm} 03569 \mathrm{f}$

[87] Kuruppuarachchi M., Savoie H., Lowry A., Alonso C., Boyle R. W.: Polyacrylamide nanoparticles as a delivery system in photodynamic therapy. Molecular Pharmaceutics, 8, 920-931 (2011).

DOI: $10.1021 / \mathrm{mp} 200023 \mathrm{y}$

[88] Dang G., Shi Y., Fu Z., Yang W.: Polymer nanoparticles with dendrimer-Ag shell and its application in catalysis. Particuology, 11, 346-352 (2013).

DOI: 10.1016/j.partic.2011.06.012

[89] Fritzen-Garcia M. B., Monteiro F. F., Cristofolini T., Acuña J. J. S., Zanetti-Ramos B. G., Oliveira I. R. W. Z., Soldi V., Pasa A. A., Creczynski-Pasa T. B.: Characterization of horseradish peroxidase immobilized on PEGylated polyurethane nanoparticles and its application for dopamine detection. Sensors and Actuators B: Chemical, 182, 264-272 (2013).

DOI: $10.1016 /$ j.snb.2013.02.107

[90] Kong X., Shi Z., Lu Z.: Synthesis of novel polymer nano-particles and their interaction with cement. Construction and Building Materials, 68, 434-443 (2014). DOI: $10.1016 /$ j.conbuildmat.2014.06.086
[91] Pu K., Shuhendler A. J., Jokerst J. V., Mei J., Gambhir S. S., Bao Z., Rao J.: Semiconducting polymer nanoparticles as photoacoustic molecular imaging probes in living mice. Nature Nanotechnology, 9, 233-239 (2014). DOI: $10.1038 /$ nnano.2013.302

[92] Mallakpour S., Abdolmaleki A., Borandeh S., Sabzalian M. R.: One pot fabrication of optically active and efficient antibacterial poly(amide-benzimidazole-imide)/Ag bionanocomposite. Journal of Polymer Research, 22, 129-136 (2015).

DOI: $10.1007 / \mathrm{s} 10965-015-0743-1$

[93] Loos C., Syrovets T., Musyanovych A., Mailänder V., Landfester K., Nienhaus G. U., Simmet T.: Functionalized polystyrene nanoparticles as a platform for studying bio-nano interactions. Beilstein Journal of Nanotechnology, 5, 2403-2412 (2014).

DOI: $10.3762 /$ bjnano. 5.250

[94] Monti D. M., Guarnieri D., Napolitano G., Piccoli R., Netti P., Fusco S., Arciello A.: Biocompatibility, uptake and endocytosis pathways of polystyrene nanoparticles in primary human renal epithelial cells. Journal of Biotechnology, 193, 3-10 (2015). DOI: $10.1016 /$ j.jbiotec.2014.11.004 